\title{
Contrasting macrophage activation by fine and ultrafine titanium dioxide particles is associated with different uptake mechanisms
}

\author{
Agnes M Scherbart ${ }^{1}$, Julia Langer ${ }^{2}$, Alexey Bushmelev ${ }^{3}$, Damiën van Berlo', Petra Haberzettl ${ }^{1}$, \\ Frederik-Jan van Schooten ${ }^{4}$, Annette M Schmidt ${ }^{3}$, Christine R Rose ${ }^{2}$, Roel PF Schins ${ }^{1}$ and Catrin Albrecht ${ }^{*}$
}

\begin{abstract}
Inhalation of (nano)particles may lead to pulmonary inflammation. However, the precise mechanisms of particle uptake and generation of inflammatory mediators by alveolar macrophages (AM) are still poorly understood. The aim of this study was to investigate the interactions between particles and AM and their associated proinflammatory effects in relation to particle size and physico-chemical properties.

NR8383 rat lung AM were treated with ultrafine (uf), fine (f) $\mathrm{TiO}_{2}$ or fine crystalline silica (DQ12 quartz). Physicochemical particle properties were investigated by transmission electron microscopy, elemental analysis and thermogravimetry. Aggregation and agglomeration tendency of the particles were determined in assay-specific suspensions by means of dynamic light scattering.

All three particle types were rapidly taken up by $\mathrm{AM}$. $\mathrm{DQ} 12$ and $\mathrm{ufTiO}_{2}$, but not $\mathrm{fTiO}_{2}$, caused increased extracellular reactive oxygen species (ROS), heme oxygenase 1 (HO-1) mRNA expression and tumor necrosis factor (TNF)- $\alpha$ release. Inducible nitric oxide synthase (iNOS) mRNA expression was increased most strongly by $\mathrm{ufTiO}_{2}$, while DQ12 exclusively triggered interleukin (IL) $1 \beta$ release. However, oscillations of intracellular calcium concentration and increased intracellular ROS were observed with all three samples. Uptake inhibition experiments with cytochalasin D, chlorpromazine and a Fcy receptor II (FcyRII) antibody revealed that the endocytosis of $\mathrm{fTiO}_{2}$ by the macrophages involves actin-dependent phagocytosis and macropinocytosis as well as clathrin-coated pit formation, whereas the uptake of ufTiO $\mathrm{I}_{2}$ was dominated by FcyllR. The uptake of DQ12 was found to be significantly reduced by all three inhibitors. Our findings suggest that the contrasting AM responses to $\mathrm{fTiO}_{2}$, $\mathrm{ufTi}_{2}$ and $\mathrm{DQ} 12$ relate to differences in the involvement of specific uptake mechanisms.
\end{abstract}

Keywords: NR8383 cells, titanium dioxide, particle internalization, size distribution, agglomeration

\section{Introduction}

The introduction and application of novel types of nanomaterials and nanodevices is rapidly increasing in recent years. Risks of exposure to nanoparticles (NP, which can be defined as nano-objects with all three external dimensions in the nanoscale, i.e. < $100 \mathrm{~nm}$; [1]) often cannot be reliably estimated at this time. Due to their novel physico-chemical properties, concerns have been raised about their potential to cause adverse effects in biological systems and their impact on human health.

\footnotetext{
* Correspondence: catrin.albrecht@uni-duesseldorf.de

'IUF - Leibniz Research Institute for Environmental Medicine, Düsseldorf, Germany

Full list of author information is available at the end of the article
}

Reliable testing strategies to investigate possible health risks caused by nanoparticles (NP) are therefore urgently needed $[2,3]$.

Hints for a potential toxicity of NP arose predominantly from the field of inhalation toxicology, where it has been shown that (aggregates of) specific NP, like carbon black (CB) or titanium dioxide $\left(\mathrm{TiO}_{2}\right)$, exhibit a markedly higher biological activity at cellular and subcellular levels $[2,4,5]$ when compared to an equal mass dose of their larger sized counterparts [6-8]. Currently, $\mathrm{TiO}_{2}$ particles are used widely and in large quantities in many industrial applications like cosmetics, pharmaceuticals, paints and in food industry, as well as in medical

\section{() Biomed Central}


and dental prosthesis in either fine (> $100 \mathrm{~nm}$ ) or ultrafine sizes $[9,10]$.

Animal studies have shown that $\mathrm{fTiO}_{2}$ particles predominantly deposit within the deeper regions of the lung and can subsequently induce inflammatory responses [11]. However, this typically does not result in marked lung fibrosis $[9,12]$, unlike other inorganic particles, e.g. crystalline silica [13-15]. Such contrasting outcomes pointed to the existence of fundamental differences between different types of inorganic particles concerning their toxic potential. Investigations of the acute inflammatory effects of an ultrafine and a fine sample of $\mathrm{TiO}_{2}$ in rats and mice have shown that the smaller particles are more potent on a mass dose basis, but that the responses do not differ when the samples are adjusted to an equal surface area dose (reviewed in [2]). This suggests that the specific surface area (SSA) of NP per se may define their pro-inflammatory effects. However, on the cellular level biological effects of NP are considered to be driven by their specific physico-chemical interactions with cells and subcellular constituents, including initial recognition and/or interference with specific membrane associated receptors [16]. This specific particle-cell-interaction may also explain observations in other studies where associations between the SSA and specific toxic effects were not as clear (e.g. [17]).

Alveolar macrophages (AM) are professional phagocytes accounting for approximately 95\% of airspace leukocytes in the healthy lung, which generally represent the first cell type that gets into contact with inhaled pathogens [18]. The AM cell line NR8383 has been extensively characterized and is widely accepted as a reliable surrogate for freshly obtained primary AM [19]. In a previous study, we demonstrated the participation of the classical phagocytosis Fc $\gamma$ receptor II (Fc $\gamma$ RII) in the uptake of fine crystalline silica particles (with a mean geometric diameter of about $1 \mu \mathrm{m}$ ) by NR8383 AM [20]. Other studies have shown an association between Fc $\gamma$ RII stimulation by interferon $\gamma$ in the monocyte cell line U937 as well as in primary human blood monocytes, and the induction of a signal cascade which is connected to phospholipase (PLC) $\gamma-1$. Activation of PLC $\gamma-1$ is known to increase the concentration of intracellular calcium $\left(\left[\mathrm{Ca}^{2+}\right]_{\mathrm{i}}\right)$ which in turn can activate nicotinamide adenine dinucleotide phosphate (NADPH) oxidases and thus the generation of ROS via the socalled oxidative burst [21,22]. Participation of other membrane receptors including the class A scavenger receptor (SR-A) and the macrophage receptor with collagenous structure (MARCO) has also been described to be of importance for the uptake of fine-sized $\mathrm{TiO}_{2}$ and silica particles, but not for the internalization of carbonaceous particles $[23,24]$. Taken together, these observations provide strong evidence that particle type-specific mechanisms of uptake exist in macrophages. However, the exact route(s) by which NP can enter these cells and their impact on subsequent cellular responses are still poorly understood. Elucidation of these mechanisms will provide an important step for the risk assessment of NP and for potential medical and pharmaceutical applications of newly engineered NP.

Interaction of AM with respirable particles can lead to the production of ROS and secretion of a large variety of cytokines, chemokines and other, typically proinflammatory mediators. These include TNF- $\alpha$ and interleukin (IL)-1 $\beta$, both early pro-inflammatory cytokines which in turn are capable to activate various secondary mediators and as such orchestrate the recruitment of further immune cells, like neutrophilic granulocytes [25]. Many of these cytokines and chemokines are regulated by redox-sensitive transcription factors like nuclear factor kappa $\mathrm{B}(\mathrm{NF}-\kappa \mathrm{B})$ and/or activator protein 1 (AP-1), which in turn are regulated by second messengers including calcium and ROS $[26,27]$. Enhanced $\left[\mathrm{Ca}^{2+}\right]_{\mathrm{i}}$ levels are known to lead to the activation of protein kinase $\mathrm{C}(\mathrm{PKC})$ which is involved in the activation of NF- $\kappa \mathrm{B}[28,29]$. The involvement of $\left[\mathrm{Ca}^{2+}\right]_{\mathrm{i}}$ in the pro-inflammatory responses of AM has recently been established for fine crystalline silica particles (54) as well as for carbonaceous NP, i.e. ultrafine carbon black [27].

In our current study, two types of $\mathrm{TiO}_{2}$ with different size distributions were investigated, i.e. $\mathrm{fTiO}_{2}$ and $\mathrm{ufTiO}_{2}$. The aims of our study were to analyze (i) differences in uptake mechanisms for these samples in $\mathrm{AM}$, and (ii) how the uptake associates with various cellular responses in AM that are considered to play a role in the adverse health effects of inhaled particles. The established inflammogenic and fibrogenic crystalline silica sample DQ12 was used as reference particle [15,30-33]. Intra- and extracellular responses of AM were investigated via the analysis of particle uptake, cytotoxicity, changes in $\left[\mathrm{Ca}^{2+}\right]_{\mathrm{i}}$, ROS generation as well as the induction of various markers of inflammation and oxidative stress, i.e. NF- $\kappa \mathrm{B}$, TNF- $\alpha$, IL- $1 \beta$, inducible nitric oxide synthase (iNOS) and heme oxygenase-1 (HO-1). Particle type-specificity of internalization by AM was investigated by uptake analysis in the absence or presence of specific inhibitors, i.e. cytochalasin D (CytD), chlorpromazine (Chl), filipin III, Fc $\gamma$ RII antibody as well as by evaluation of uptake at 4 versus $37^{\circ} \mathrm{C}$. Since former studies have shown that $\mathrm{TiO}_{2}$ particles tend to reside as aggregates as well as to form larger agglomerates in suspension depending on the type of buffers [34], in the present study special emphasis was also put on the characterization of the specific particle suspensions used for the various biological tests. Elemental analysis (EA) and thermogravimetric analysis 
(TGA) have been employed to exclude the presence of organic residues in the investigated powders that could impact on AM responses. Morphology and dispersion behavior of the samples in the different media was evaluated by means of transmission electron microscopy (TEM), dynamic light scattering (DLS) and dark field light scattering microscopy (DF-LSM).

\section{Materials and methods}

\section{Particle samples used}

Three types of particles were used in this study, i.e. ufTiO 2 and $\mathrm{fTiO}_{2}$ and a respirable quartz sample (DQ12). $\mathrm{fTiO}_{2}$ was obtained from Sigma-Aldrich and is a pure anatase sample with a reported mean diameter of about $250 \mathrm{~nm}$ [8]. The ufTiO ${ }_{2}$ sample originates from Degussa (Hanau, Germany) and represents a mixture of $80 \%$ anatase and $20 \%$ rutile with a reported mean particle size of $25 \mathrm{~nm}$ [8]. The DQ12 sample originates from Dörentrup, Germany (IUF batch 6) and represents a highly pure quartz (99.1\%) with a mean particle diameter of $960 \mathrm{~nm}$ [32]. The specific surface areas of the samples measured according to the method of Brunauer, Emmert and Teller [35] are $50 \mathrm{~m}^{2} / \mathrm{g}, 10 \mathrm{~m}^{2} / \mathrm{g}$ and 9.6 $\mathrm{m}^{2} / \mathrm{g}$, for ufTiO${ }_{2}, \mathrm{fTiO}_{2}$ and DQ12, respectively.

\section{Particle characterization}

In order to obtain additional information on particle composition and size, the batches were subjected to TGA, EA, DLS, DF-LSM and TEM. EA of the powders was carried out with a Perkin-Elmer Analyzer 2400 with an accuracy of measurement of $0.3 \%$. TGA experiments were performed on powder samples on a Netsch STA 449 C Jupiter at a constant heating rate of $10 \mathrm{~K} \mathrm{~min}^{-1}$ in an argon atmosphere between 30 and $600^{\circ} \mathrm{C}$. The solid residues at $600^{\circ} \mathrm{C}$ are attributed to the inorganic component. TEM images were taken using a Philips EM 208 S. DLS measurements were performed on a High-Performance Particle Sizer HPP5002 (Malvern Instruments) after their suspension in water, Hank's buffered saline solution (HBSS ${ }^{(++)}$, phenol red free, with $\mathrm{Mg}^{2+}$ and $\mathrm{Ca}^{2+}$; Invitrogen $\mathrm{GmbH}$, Karlsruhe, Germany) and FCS-containing cell culture medium at $25^{\circ} \mathrm{C}$, using $1 \times 1 \mathrm{~cm}^{2}$ polystyrene cuvettes. Particle size distributions were derived from a deconvolution of the measured intensity autocorrelation function by the non-negative least-squares algorithm included in the DTS software. The suspensions used for this analysis were prepared in the same way as those used for the biological testing as described below. DLS analysis of the $\mathrm{ufTiO}_{2}$ particle suspension was also performed after filtration through a $450 \mathrm{~nm}$ membrane filter to further evaluate the influence of aggregate/agglomerate formation on this method.

\section{Preparation of the particle suspensions and cell treatments}

NR8383 rat AM (ATCC, Manassas, USA) were cultured in Kaighn's modified medium (F12-K Nutrient Mixture, Gibco, Eggenstein, Germany) containing 15\% FCS, 1\% penicillin/streptomycin and 1\% glutamine (all purchased from Sigma-Aldrich, Taufkirchen, Germany) and incubated in a humidified incubator (Heraeus, BB $6060 \mathrm{CU}$ ) at $37^{\circ} \mathrm{C}$ and $5 \% \mathrm{CO}_{2}$. Three days before each experiment, cells were seeded in a concentration of $1.25 \times 10^{5}$ cells/ $\mathrm{cm}^{2}$ in the indicated culture dishes. If not otherwise mentioned, incubations took place at $37^{\circ} \mathrm{C}$ and $5 \% \mathrm{CO}_{2}$.

Particles were heated at $220^{\circ} \mathrm{C}$ for $16 \mathrm{~h}$ in order to destroy potential endotoxins, which are known to be potent activators of AM. Immediately before the experiment, particles were freshly suspended either in complete cell culture medium (see above) for most of the experiments except for ROS and calcium measurements, for which suspension was performed in $\mathrm{HBSS}^{(+/)}$(phenol red free, with $\mathrm{Mg}^{2+}$ and $\mathrm{Ca}^{2+}$ ) or saline, respectively. The evaluation of mRNA expression changes was done under both treatment conditions, i.e. using particles suspended in either $\mathrm{HBSS}^{(+/+)}$or complete medium. All suspensions were sonicated in a water bath for $10 \mathrm{~min}$ (Sonorex TK 52, Schaltech, Mörfelden-Walldorf, Germany) immediately prior to addition to the cells. Particles were added to the AM at concentrations of 10, 20, $40,80 \mu \mathrm{g} / \mathrm{cm}^{2}$ for 1,4 or $24 \mathrm{~h}$ as indicated.

\section{Measurement of particle uptake by flow cytometry}

The uptake of particles by the AM was analyzed via flow cytometry. Measurement was performed with a FACS Calibur (Becton Dickinson, Heidelberg, Germany). The sideward scatter (SSC) which is directly related to cell granularity was used as a marker of particle uptake [36], whereas the forward scatter (FSC) mainly correlates to the cell size.

For inhibition experiments, cells were preincubated for 30 min with the following substances: CytD $(1.5 \mu \mathrm{g} / \mathrm{mL}$; Sigma, Taufkirchen, Germany) to inhibit actin recruitment, Chl (5 $\mu \mathrm{g} / \mathrm{mL}$; Sigma-Aldrich, Taufkirchen, Germany) to disable the formation of clathrin coated pits (CCP), and an antibody against the phagocytotic Fc $\gamma$ RII (CD32, $5 \mu \mathrm{g} / \mathrm{mL}$; BD Biosciences, Heidelberg, Germany) to avoid specific receptor binding. Dimethyl sulphoxide (DMSO, 0.1\%; Sigma, Taufkirchen, Germany) was applied as vehicle control for CytD. The IgG $1 \kappa$ monoclonal antibody was used as isotype control $(5 \mu \mathrm{g} / \mathrm{mL}$; BD Biosciences, Heidelberg, Germany) for the Fc $\gamma$ RII antibody experiments. Cells were treated with particles at concentrations of 10,20 or $40 \mu \mathrm{g} / \mathrm{cm}^{2}$ for 1 or $3 \mathrm{~h}$. NR8383 cells were gently scraped from the culture dishes on ice, centrifuged $\left(200 \times \mathrm{g}, 10 \mathrm{~min}, 4^{\circ} \mathrm{C}\right)$, washed with $300 \mu \mathrm{l}$ of ice cold $\mathrm{HBSS}^{(-/)}$and centrifuged again. 
The pellet was resuspended in $200 \mu \mathrm{l}$ ice cold $\mathrm{HBSS}^{(-/)}$. In total 15,000 events were counted. For calculation cell debris and free particles were excluded by an electronical gate containing AM of all sizes and granularities in a FSC-SSC-histogram. Univariant histograms of SSC determined the median of cell granularity used as measure of particle uptake by AM. Data were detected with CellQuest 3.3 and analyzed using CellQuest Pro (Becton Dickinson, Heidelberg, Germany).

\section{Microscopical evaluation of uptake}

In order to microscopically investigate AM after a $24 \mathrm{~h}$ treatment with particles cytospin slides were prepared. Therefore, NR8383 cells were scraped, centrifuged (200 $\times \mathrm{g}, 5 \mathrm{~min}, 4^{\circ} \mathrm{C}$ ), washed and resuspended in sterile, ice cold phosphate buffered saline (PBS). Then $2 \times 10^{5}$ cells were spun onto glass slides (600 rpm, $5 \mathrm{~min})$ using a Cytospin3 (Shandon GmbH, Frankfurt, Germany). After drying and May-Grünwald-Giemsa-staining (Merck, Darmstadt, Germany) preparations were analyzed via light microscopy (Olympus BX60, Hamburg, Germany).

\section{Cytotoxicity}

Effects of particles on cell viability were determined using the WST-1 assay (Roche Diagnostics GmbH, Mannheim, Germany) which is based on the principle of the reduction of the stable tetrazolium salt WST-1 to a soluble violet formazan product within the mitochondria of viable cells. For this assay, NR8383 cells were seeded in octoplicate in 96-well microtiter plates. After $24 \mathrm{~h}$ of particle treatment, $10 \mu \mathrm{L}$ WST-1 solution (Roche Diagnostics $\mathrm{GmbH}$, Mannheim, Germany) was added to 5 wells per treatment or control and incubated for further $2 \mathrm{~h}$. The other three wells were used as controls for the absorption by the particles and therefore measured without WST-1 substrate application. Optical density was detected at $450 \mathrm{~nm}$ using the Multiskan ELISA reader (Thermo Fisher Scientific, Dreieich, Germany). For data calculation, the mean of the obtained values of the wells without WST-1 was subtracted from the mean of the WST-1 substrate treated samples and expressed as percentage of control cells. To investigate potential reagent binding to particles, which could lead to a false interpretation of toxicity [3], cell free experiments were performed in WST-1- as well as formazan-containing suspensions spiked with particles. Such artifacts could be excluded for the particles used in our present study.

\section{Calcium imaging}

In order to investigate the relation between particle exposure and intracellular calcium, wide-field fluorescent imaging was employed to measure changes in $\left[\mathrm{Ca}^{2}\right.$ $\left.{ }^{+}\right]_{\mathrm{i}}$ in individual cultured AM upon particle treatment. NR8383 cells were seeded onto sterile coverslips coated with poly-D-lysine hydrobromide (Sigma-Aldrich, Taufkirchen, Germany) and used for experiments after $3-4$ days. Loading with the $\mathrm{Ca}^{2+}$ sensitive fluorescent dye Fura- 2 and fluorescence measurements were performed in saline containing (in $\mathrm{mM}$ ): $\mathrm{NaCl} 125, \mathrm{KCl} 3, \mathrm{NaH}_{2}$ $\mathrm{PO}_{4} 1.25, \mathrm{MgSO}_{4} 2, \mathrm{CaCl}_{2}$ 2, HEPES 25, D-glucose 10 (pH 7.4). The acetoxymethyl ester form of the fluorophore was dissolved as $5 \mathrm{mM}$ stock solution in $20 \%$ Pluronic acid in DMSO and stored at $-20^{\circ} \mathrm{C}$. For dye loading, coverslips were incubated for $90 \mathrm{~min}$ at room temperature in saline containing $0.5 \mathrm{mM}$ Fura-2- acetoxymethyl ester. Following loading, cells were kept in dye-free saline for at least $30 \mathrm{~min}$ to ensure de-esterification of the dye before starting the imaging experiments.

Conventional wide-field fluorescent imaging was performed employing an imaging system (Till Photonics $\mathrm{GmbH}$, Munich, Germany) in conjunction with an upright microscope (Axioskop, Zeiss, Oberkochen, Germany) equipped with a cooled CCD camera (SensiCam QE, PCO, Kelheim, Germany). Cells loaded with Fura-2 were excited every $5 \mathrm{~s}$ using a monochromator (polychrome V, Till Photonics GmbH); fluorescence emission from regions of interest (ROIs) placed around AM somata was detected by the camera. Emission intensities $>440 \mathrm{~nm}$ were collected after alternate excitation at 357 and $380 \mathrm{~nm}$, and background-corrected fluorescent ratios (F357/380) were calculated. Background fluorescence was determined from coverslip areas devoid of cellular material.

Baseline $\left[\mathrm{Ca}^{2+}\right]_{i}$ was recorded under control conditions and for at least $70 \mathrm{~min}$ during exposure to either ufTiO or $\mathrm{fTiO}_{2}$ particles at concentrations of 10 or $20 \mu \mathrm{g} / \mathrm{cm}^{2}$. To quantitatively analyze and compare calcium fluctuations in response to different particles, integrals for ratio values for specific $10 \mathrm{~min}$ time windows (one for control experiments; 15 - $25 \mathrm{~min}$ and 55 - 65 min after particle application) were calculated for each individual cell employing OriginPro Software (OriginLab Corporation, Northampton, MA).

\section{Intracellular ROS measured by DCFH-DA}

To quantify intracellular ROS the cell-permeable nonfluorescent probe 2',7'-dichlorodihydrofluorescein diacetate (DCFH-DA; Sigma, Saint-Louis, Missouri, USA) was used. After entering the cell, DCFH-DA loses its diacetate group by the action of esterases. The oxidation of this probe leads to the highly fluorescent DCF. Prior to particle treatment, NR8383 cells seeded in 96-well plates were washed and replaced by $\mathrm{HBSS}^{(+/+)}$to avoid scavenging effects of DCFH-DA by medium components. After a recovery time of $30 \mathrm{~min}$, AM were preincubated with $100 \mu \mathrm{M}$ DCFH-DA for another $20 \mathrm{~min}$ in the incubator. Afterwards cells were washed and 
allowed to recover for another $30 \mathrm{~min}$ before they were treated with $40 \mu \mathrm{g} / \mathrm{cm}^{2}$ of particles. The change in DCFH-DA fluorescence over time was detected via fluorescence reader (Synergy2, BioTek Instruments Inc., Bad Reichenhall, Germany) for $3 \mathrm{~h}$ at $37^{\circ} \mathrm{C}$.

\section{Measurement of extracellular ROS by Electron Paramagnetic Resonance (EPR) spectroscopy with spin trapping}

For the analysis of extracellular ROS, NR8383 cells were seeded in 96 well plates. Cells were washed and the medium was replaced by $\mathrm{HBSS}^{(+/+)}$followed by a recovery time of $30 \mathrm{~min}$. AM were treated with particles at concentrations of 10 or $40 \mu \mathrm{g} / \mathrm{cm}^{2}$. The spin trapping agent 5,5-dimethyl-1-pyroline-N-oxide (DMPO, 0.11 M, Sigma-Aldrich, Taufkirchen, Germany) was added simultaneously with the particles; cells were incubated for $3 \mathrm{~h}$. Cell-free supernatants were harvested and immediately measured for radical formation using a MiniScope MS200 Spectrometer (Magnettech, Berlin, Germany) with the following instrumental settings: room temperature, microwave frequency $=9.39 \mathrm{GHz}$, magnetic field $=3360 \mathrm{G}$, sweep width $=100 \mathrm{G}$, scan time $=30 \mathrm{~s}$, number of scans $=3$, modulation amplitude $=2 \mathrm{G}$, receiver gain $=900$. Quantification was carried out on first derivation of EPR signal of the characteristic DMPO-OH quartet, as the mean of amplitudes, and outcomes are expressed in arbitrary units (a.u.). DQ12 and the well-known PKC activator phorbol 12-myristate 13-acetate (PMA) were used as positive controls.

\section{Immunocytochemistry (IHC) for NF- $\kappa$ B}

Transcriptional activation of the nuclear factor $\kappa \mathrm{B}$ was microscopically analyzed by the nuclear translocation of the p65 subunit. Therefore, cells were seeded into 4chamber slides and treated with $40 \mu \mathrm{g} / \mathrm{cm}^{2}$ of particles. After $1 \mathrm{~h}, \mathrm{NR} 8383$ cells were fixed (4\% paraformaldehyde/PBS, pH 7.4) and permeabilized (0.1\% TritonX-100, $5 \mathrm{~min}$ ). Unspecific binding sites were blocked by goat normal serum followed by an overnight incubation with anti-NF- $\kappa$ B (p65) antibody (1:500, Santa Cruz Biotechnology, CA, USA). Slides were incubated with secondary antibody Alexa-488 (1:200, Molecular Probes, OR, USA) for $1 \mathrm{~h}$ before mounting the cover slip with Ultra Cruz Mounting Medium containing DAPI (Santa Cruz Biotechnology, CA, USA). Fluorescence images were taken with the Axio Observer.D1 fluorescence microscope (Carl Zeiss MicroImaging GmbH, Göttingen, Germany).

\section{TNF- $\alpha$ and IL- $1 \beta$ release}

NR8383 cells were seeded onto 24-well microtiter plates. After $24 \mathrm{~h}$ of particle treatment, cell-free supernatant was collected, centrifuged $\left(200 \times \mathrm{g}, 10 \mathrm{~min}, 4^{\circ} \mathrm{C}\right)$ and aliquots were stored at $-20^{\circ} \mathrm{C}$. Supernatants were analyzed using a TNF- $\alpha$ or IL- $1 \beta$ ELISA kit (R\&D Systems, Wiesbaden, Germany) according to the manufacturer's manual and using a Multiskan ELISA reader (Thermo Fisher Scientific, Dreieich, Germany).

\section{Quantitative RT-PCR analysis of gene expression}

NR8383 cells were seeded in 6-well plates, treated with particles for $4 \mathrm{~h}$, scraped and centrifuged $(200 \times \mathrm{g}, 5$ min, $\left.4^{\circ} \mathrm{C}\right)$. The pellet was resuspended in $0.5 \mathrm{ml} \mathrm{Trizol}{ }^{\circledR}$ Reagent (Invitrogen $\mathrm{GmbH}$, Karlsruhe, Germany) and stored at $-20^{\circ} \mathrm{C}$ until further use. The RNeasy ${ }^{\circledR}$ mini kit (Qiagen, Hilden, Germany) coupled to DNAse treatment was used to purify total RNA from salts and residual DNA. Quantity and purity of RNA were evaluated using spectrophotometry at 230, 260, 280, and $320 \mathrm{~nm}$. cDNA was synthesized using the iScript ${ }^{\mathrm{TM}} \mathrm{CDNA}$ Synthesis kit (BioRad, CA, USA), starting from $0.5 \mu \mathrm{g}$ of RNA. cDNA was diluted $15 \times$ in RNAse-free water before use. PCR primers for rat $\mathrm{HO}-1$, iNOS and the housekeeping gene GAPDH were designed using Primer Express software (Applied Biosystems). Primer sequences for $\mathrm{HO}-1$ were 5'-GGG AAG GCC TGG CTT TTTT -3' (forward) and 5'-CAC GAT AGA GCT GTT TGA ACT TGGT -3' (reverse), for iNOS 5'-AGG AGA GAG ATC CGG TTC ACA GT-3' (forward) and 5'-ACC TTC CGC ATT AGC ACA GAA-3' (reverse) and for GAPDH 5'-TGA TTC TAC CCA CGG CAA GTT-3' (forward) and 5'TGA TGG GTT TCC CAT TGA TGA-3' (reverse). qRT-PCR was performed with a MyiQ Single Color real time PCR detection system (BioRad) using $\mathrm{iQ}^{\mathrm{TM}} \mathrm{SYBR}^{\circledR}$ Green Supermix (Biorad), $5 \mu \mathrm{L}$ diluted cDNA, and 2.5 $\mu \mathrm{L}$ of $0.3 \mu \mathrm{M}$ forward and reverse primer in a total volume of $25 \mu \mathrm{L}$. PCR was conducted as follows: a denaturation step at $95^{\circ} \mathrm{C}$ for $3 \mathrm{~min}$ was followed by 40 cycles at $95^{\circ} \mathrm{C}(15 \mathrm{~s})$ and $60^{\circ} \mathrm{C}(45 \mathrm{~s})$. After PCR, a melt curve $\left(60-95^{\circ} \mathrm{C}\right)$ was generated for product identification and purity. PCR efficiency of all four primer sets, as assessed by the use of cDNA dilution curves, was 90 $100 \%$. Data were analyzed using the MyiQ Software system (BioRad) and were expressed as relative gene expression (fold increase) using the $2^{-\Delta \Delta \mathrm{Ct}}$ method [37].

\section{Statistical Analysis}

All biological assays were performed in at least three independent experiments. Data are presented as mean \pm SEM unless indicated otherwise. Statistical analysis was performed using SPSS 18.0 for Windows using analysis of variance (ANOVA) with Dunnett or LSD post hoc comparison as indicated for the specific data. Differences compared to untreated control cells were considered significant at * $\mathrm{p}<0.05, * * \mathrm{p}<0.01$ and $* * \mathrm{p}<$ 0.001 . Differences in inhibition experiments compared to the appropriate particle treatment were indicated as \# $\mathrm{p}<0.05$, \#\# $\mathrm{p}<0.01$ and \#\#\# $\mathrm{p}<0.001$. 


\section{Results}

\section{Particle sample characteristics}

In order to verify the absence of organic residues in the particle samples, we performed EA and TGA in the powders. In the former, no carbon content was detected within the experimental error, and in the latter, no significant weight loss was found attributable to organic combustible contents, up to a temperature of $600^{\circ} \mathrm{C}$ (data not shown). The morphology of the samples was investigated by means of TEM. Representative images (Figure 1) showed for the $\mathrm{TiO}_{2}$ samples individual particles of nearly spherical shape and moderate size distribution. From the images, particle size histograms were extracted (see Figure 1D), revealing a number-average primary particle diameter of $69.1 \mathrm{~nm}( \pm 39.9 \mathrm{~nm} \mathrm{SD})$ for $\mathrm{ufTiO}_{2}$ particles and of $194.9 \mathrm{~nm}( \pm 60.8 \mathrm{~nm} \mathrm{SD})$ for $\mathrm{fTiO}_{2}$, respectively. Figure $1 \mathrm{C}$ shows a representative image of the control sample DQ12. A detailed characterization of this sample has been performed in a previous study, revealing a mean diameter of $960 \mathrm{~nm}$ [32].

\section{Evaluation of particle suspensions used for biological testing}

It is well-known that for (nano)particle dispersions the actual object size can differ significantly from the size of the primary particles and their aggregates due to agglomeration processes. Therefore, we compared the core size of the primary particles obtained from TEM with results from dispersion-based methods. For this
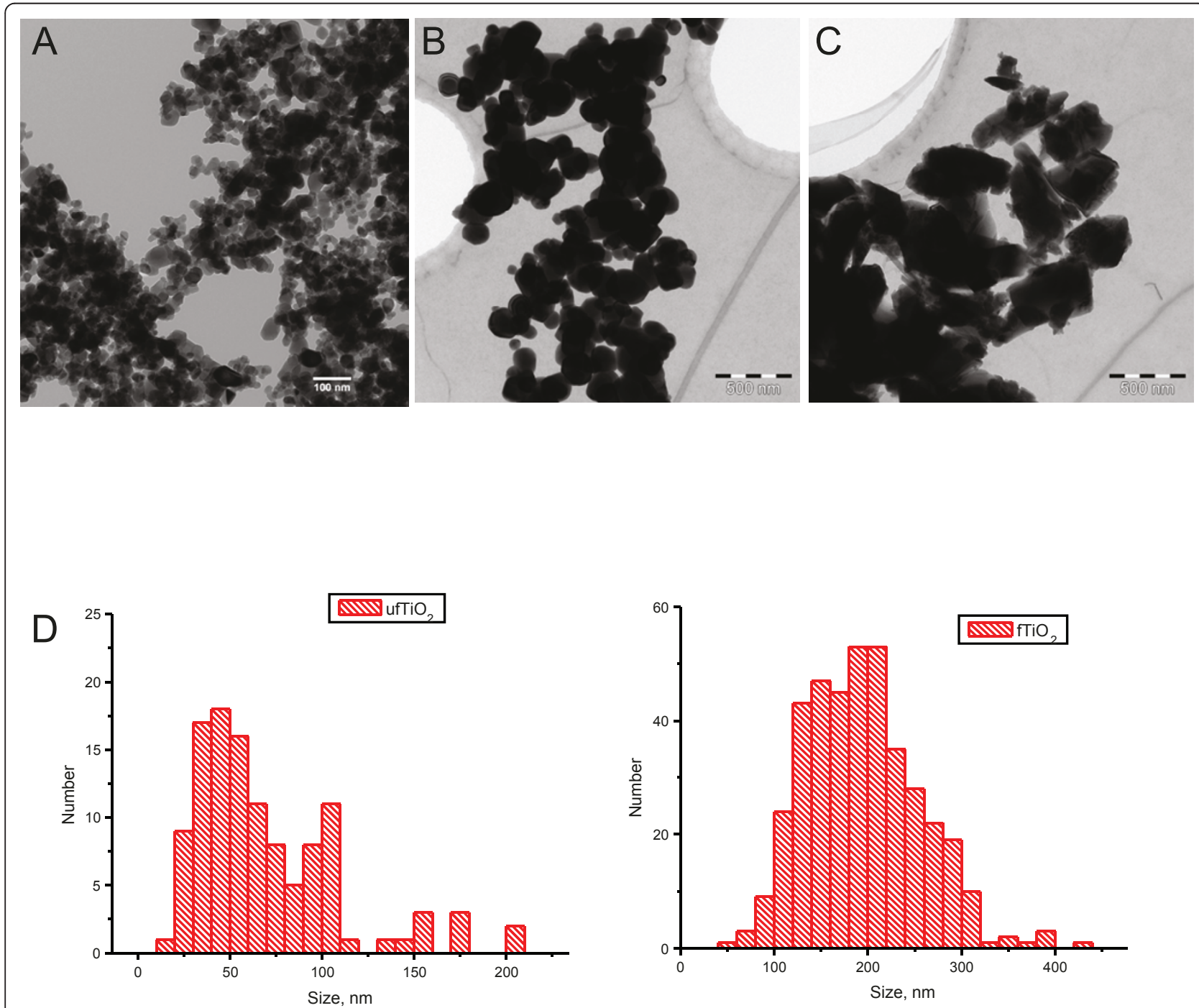

Figure 1 TEM images and size distribution of particles. Particles were suspended and prepared for TEM measurements in deionized water (A) $\mathrm{UfTiO}_{2}$ and (B) $\mathrm{fTiO}_{2}$ are regular and spherical particles in contrast to (C) crystalline silica DQ12 particles that display a very irregular shape. (D) Particle size histograms are derived from the appropriate TEM analysis for primary particles of $\mathrm{UfTO}_{2}$ and $\mathrm{fTiO}_{2}$. 
purpose, DLS and DF-LSM experiments were carried out. Both methods are based on the analysis of the distribution of the diffusion coefficient measured from scattered light signals. While in DLS the signal fluctuations are used directly to obtain information on the autocorrelation function, in DF-LSM the signals are used to track individual objects and analyze their Brownian diffusion perpendicular to the laser direction. For uf $\mathrm{TiO}_{2}$ as well as $\mathrm{fTiO}_{2}$, particle dynamics as examined by DLS were in accordance with the presence of predominantly primary particles or small aggregates in water dispersion after ultrasonification and partly filtration by a $450 \mathrm{~nm}$ microfilter. This is evident from the high correlation of the number-average hydrodynamic particle diameter as extracted by DLS (see Table 1) with the average core diameter as observed by TEM. Similar values were also obtained for the cell culture-based particle dispersions. In the latter, after filtration which was performed to investigate the impact of aggregate/ agglomerate formation on the DLS measurements, the scattering signal was dominated by small colloids $(\sim 6$ $\mathrm{nm}$ ). This signal could be attributed to proteins which are abundant in the FSC containing medium. The proteins contained within the FCS stabilize the particles in the dispersion and hence prevent their sedimentation. In the HBSS-based suspensions, however, the DLS measurements indicated the presence of agglomerates with a diameter of up to the micrometer range (see Table 1, value in brackets). The findings are in accordance with the observation of a lower sedimentation stability of these buffer-based samples compared to water- or complete culture medium-based dispersions.

Importantly, for the uf $\mathrm{TiO}_{2}$ particles the mass percentage of the filtered fraction was $20 \%$ of the total mass (data not shown). The large fraction of the non-filtered material at least in part accounts for larger agglomerates which may be inappropriately measured by the DLS method. As such, the data of the unfiltered samples

Table 1 Characteristics of particle dispersions as measured by DLS

\begin{tabular}{|c|c|c|c|}
\hline sample & Dispersant & $d_{\mathrm{h}}^{\mathrm{a}}$ & $\mathrm{PDI}^{\mathrm{b}}$ \\
\hline \multirow{3}{*}{ ufTiO $_{2}$} & water & $\begin{array}{c}55.4^{C} \\
(891.2)\end{array}$ & 0.22 \\
\hline & cell culture medium & 57.5 & 0.33 \\
\hline & HBSS & $\begin{array}{l}164.2^{c} \\
(2018)\end{array}$ & 0.26 \\
\hline \multirow{3}{*}{$\mathrm{fTiO}_{2}$} & Water & 321.2 & 0.18 \\
\hline & cell culture medium & 448.6 & 0.16 \\
\hline & HBSS & 936.6 & 0.64 \\
\hline \multicolumn{4}{|c|}{${ }^{a}$ number-average hydrodynamic diameter [nm] } \\
\hline \multicolumn{4}{|c|}{ b polydispersity index } \\
\hline \multicolumn{4}{|c|}{ c sample was filtered (450 nm microfilter) prior to experiment } \\
\hline
\end{tabular}

have to be interpreted with caution. Nevertheless, the measurements of the unfiltered suspensions (Table 1) showed that the ultrafines tended to from larger agglomerates than their fine counterparts. These findings were also supported by data obtained from DFLSM (not shown), and are important in view of the cell based assays.

\section{Dose-dependent particle uptake in alveolar macrophages}

The uptake of particles by NR8383 AM was determined by measuring the granularity of the cells via flow cytometry. These measurements revealed a dose-dependent uptake $\left(10,20\right.$ or $\left.40 \mu \mathrm{g} / \mathrm{cm}^{2}\right)$ of all tested particles after 1 as well as $3 \mathrm{~h}$ (Figure 2, panels A-C). Comparison of the SSC results also indicates that the smaller the ingested particles, the higher is the light scattering caused by the elevated granularity of the cells. This was confirmed by comparison of cell free particle suspensions revealing a median SSC of 885, 728 or 228 for $\mathrm{ufTiO}_{2}, \mathrm{fTiO}_{2}$ or DQ12, respectively. Uptake was also verified by light microscopy of treated NR8383 cells (Figure 2D).

\section{Cell toxicity following particle exposure}

Viability of AM after 4 and 24 h of particle treatment was determined by measurement of mitochondrial dehydrogenase activity. This investigation showed no cytotoxic effects after $4 \mathrm{~h}$ for all three tested particles (Figure 3A) but marked differences between $\mathrm{fTiO}_{2}$ and $\mathrm{ufTiO}_{2}$ particles after $24 \mathrm{~h}$ (Figure 3B). Treatment of the $\mathrm{AM}$ with $\mathrm{ufTiO}_{2}$ particles already caused toxic responses at a concentration of $20 \mu \mathrm{g} / \mathrm{cm}^{2}$ which was comparable to the responses of the positive control DQ12. For $\mathrm{fTiO}_{2}$ particles no effects on cell viability were found up to the highest tested concentration of $80 \mu \mathrm{g} / \mathrm{cm}^{2}$.

\section{Ultrafine and fine $\mathrm{TiO}_{2}$ exposure induce intracellular increase of calcium}

Calcium is an important second messenger involved in a multitude of intracellular signaling pathways. We, therefore, investigated the impact of exposure to $\mathrm{TiO}_{2}$ particles on the calcium concentration $\left(\left[\mathrm{Ca}^{2+}\right]_{\mathrm{i}}\right)$ of individual AM by performing ratiometric imaging with Fura-2 (Figure 4A). Under control conditions with no added particles, the baseline calcium concentration was stable (Figure 4B). Addition of either $\mathrm{ufTiO}_{2}$ or $\mathrm{fTiO}_{2}$ caused an increase in the intracellular calcium concentration in a large number of cells in the field of view, some cells responded with large and random calcium oscillations (Figure 4C).

To quantitatively analyze and compare calcium fluctuations in response to different particles and different concentrations, integrals for ratio values for specific 10 min time windows (one for control experiments; $15-25$ 
A

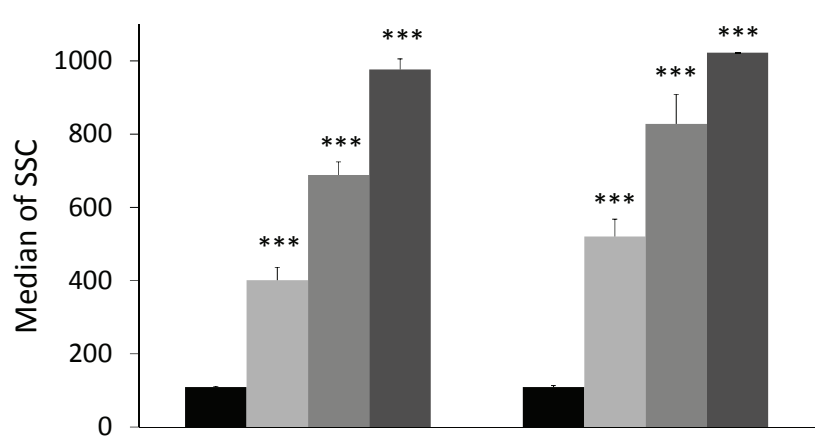

B

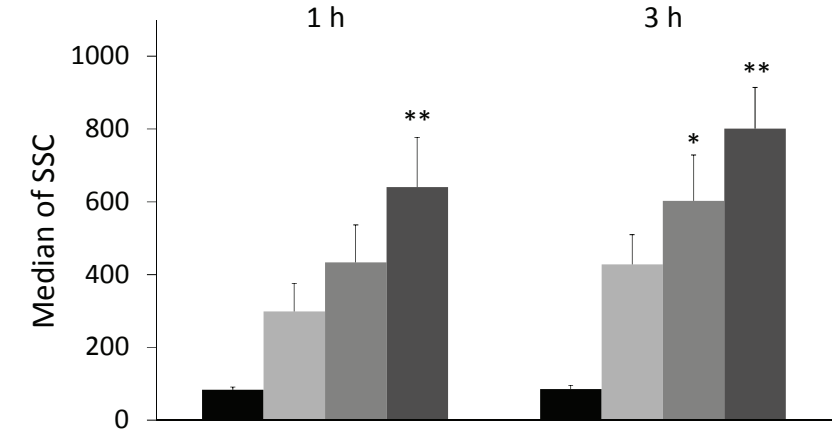

$3 \mathrm{~h}$

C
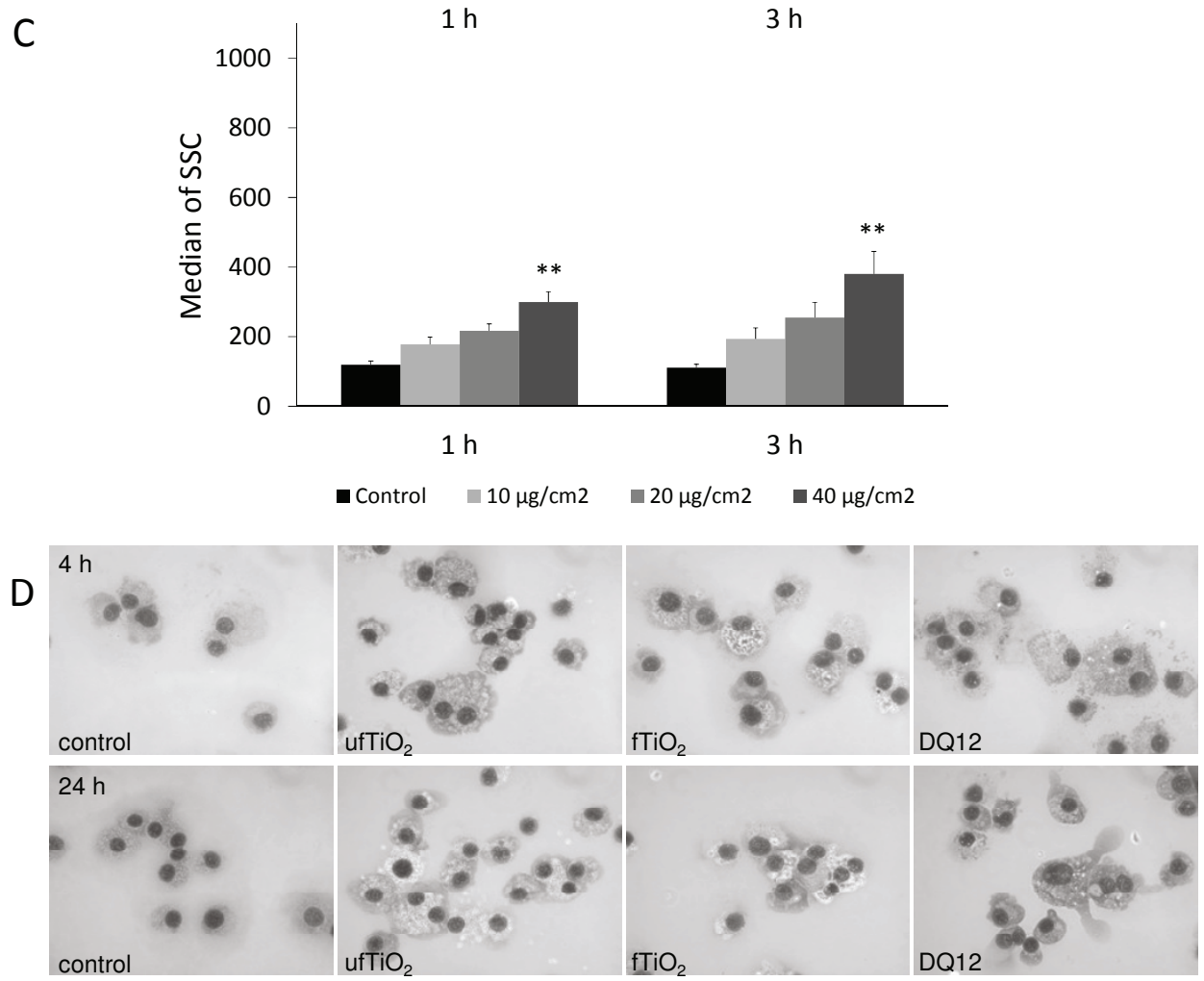

Figure 2 Concentration- and time-dependent particle uptake by NR8383 cells. Results of FACS analysis demonstrate increased particle uptake by AM based on SSC of laser light indicating cellular granularity. AM were treated with (A) $\mathrm{UfTiO}_{2}$, (B) $\mathrm{fTiO}_{2}$ and (C) DQ12 particles in concentrations of 10,20 or $40 \mu \mathrm{g} / \mathrm{cm}^{2}$ for 1 or $3 \mathrm{~h}$. (D) Particle internalization by NR8383 cells are demonstrated in MGG-stained cytospin preparations. Light microscopic images show AM either untreated or treated with $10 \mu \mathrm{g} / \mathrm{cm}^{2}$ of particles for $4 \mathrm{~h}$ (upper panel) or $24 \mathrm{~h}$ (lower panel). Original magnification 1000-fold (Olympus BX60). Figure A - C represent median \pm SEM of three independent experiments, with * $p<$ $0.05,{ }^{* *} p<0.01$ and ${ }^{* * *} p<0.001$ vs. control (ANOVA with Dunnett post-hoc comparison). 


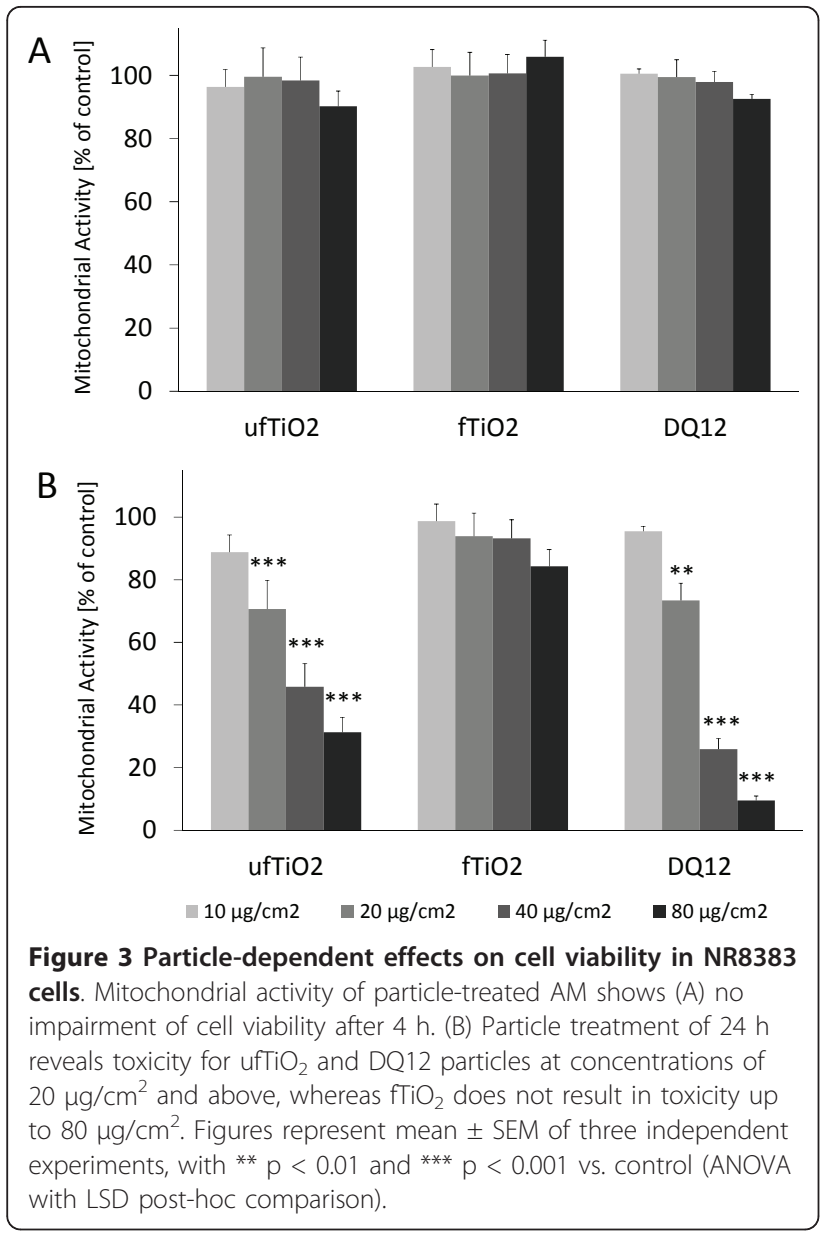

min and 55 - 65 min after particle application) were calculated for each individual cell (Figure 4D). The resulting integral values were normalized to the mean of control values (obtained in the absence of particles). Cells, displaying values not covered by the standard deviation of control, were classified as "activated". A small number of such activated cells $(8-10 \%)$ were already found in the control (Figure 4D, upper histograms). After addition of particles, however, the number of activated cells increased to $30-70 \%$ (Figure 4D). No consistent differences in percentage of activated cells nor amplitude of calcium fluctuations were found between ufTiO 2 and $\mathrm{fTiO}_{2}$.

\section{Particle-induced intracellular ROS generation}

To study the ability of ufTiO ${ }_{2}, \mathrm{fTiO}_{2}$ and DQ12 particles to cause ROS generation in the NR8383 cells, measurements were conducted over a period of $3 \mathrm{~h}$. Formation of the fluorescent DCF, representing intracellular ROS formation within the particle treated AM is shown in Figure 5A. Intracellularly generated ROS were clearly observed upon particle treatment compared to untreated NR8383 cells. No significant differences were found between the different types of particles.

\section{Particle-induced extracellular ROS generation}

Extracellular ROS were detected upon $3 \mathrm{~h}$ of particle treatment in the supernatant of NR8383 cells by EPR coupled to spin trapping with DMPO. Results are shown in Figure 5B. A clear dose dependency was observed for all three particle types, with effects reaching statistical significance for $\mathrm{ufTiO}_{2}$ and DQ12 at the higher concentration of $40 \mu \mathrm{g} / \mathrm{cm}^{2}$.

Induction of markers of oxidative stress and inflammation ROS as well as $\left[\mathrm{Ca}^{2+}\right]_{\mathrm{i}}$ are known to play an important role in activating several signaling pathways such as MAP kinases and redox-sensitive transcription factors including NF- $\kappa \mathrm{B}$, which can lead to the production of pro-inflammatory molecules and mediators. Therefore, we investigated the effects of the different particles on NF- $\kappa$ B activation, release of TNF- $\alpha$ and IL- $1 \beta$ as well as changes in mRNA expression of HO-1 and iNOS in NR8383 cells. In non-activated cells, NF- $\kappa$ B-specific fluorescence, reported by an antibody against RelA(p65), was located in the cytoplasm of the AM as shown in Figure 6A. A distinct increase in nuclear fluorescence staining, indicating activation of the NF- $\kappa \mathrm{B}$ pathway, was seen after treatment with the positive control DQ12 (Figure 6B). Treatment of NR8383 cells with ufTiO (Figure 6D) was found to cause an increase in the nuclear p65 staining albeit less strong than that following DQ12 treatment. Treatment with $\mathrm{fTiO}_{2}$ showed a weak signal (Figure 6C).

The ability of the different particle types to induce TNF- $\alpha$ and IL- $1 \beta$ release from NR8383 cells is shown in Figure 7. TNF- $\alpha$ release was found to be induced by uf $\mathrm{TiO}_{2}$ particles in a concentration-dependent manner, but not by $\mathrm{fTiO}_{2}$ particles (Figure 7A). DQ12 was the most potent particle type, showing a significantly increased TNF- $\alpha$ release at $40 \mu \mathrm{g} / \mathrm{cm}^{2}$, whereas a significant effect for ufTiO ${ }_{2}$ was only found at the highest concentration tested $\left(80 \mu \mathrm{g} / \mathrm{cm}^{2}\right)$. In contrast to the observations for TNF- $\alpha$, the release of IL- $1 \beta$ from NR8383 cells was only increased after treatment with DQ12 particles (Figure 7B). Neither $\mathrm{ufTiO}_{2}$ nor $\mathrm{fTiO}_{2}$ were capable of initiating an increased IL- $1 \beta$ release from NR8383 cells at the concentrations tested.

Results of qRT-PCR analyses of the stress response gene $\mathrm{HO}-1$ and the inflammatory gene iNOS are shown in Figure 8 after treatment of the cells in complete culture medium ( $8 \mathrm{~A}$ and $8 \mathrm{C}$ ) or in HBSS ( $8 \mathrm{~B}$ and $8 \mathrm{D}$ ), respectively. Under full medium conditions, a significant higher HO-1 and iNOS mRNA expression was observed after $4 \mathrm{~h}$ incubation with $40 \mu \mathrm{g} / \mathrm{cm}^{2} \mathrm{ufTiO}_{2}$ as well as DQ12. When treated with HBSS suspensions, the ability 

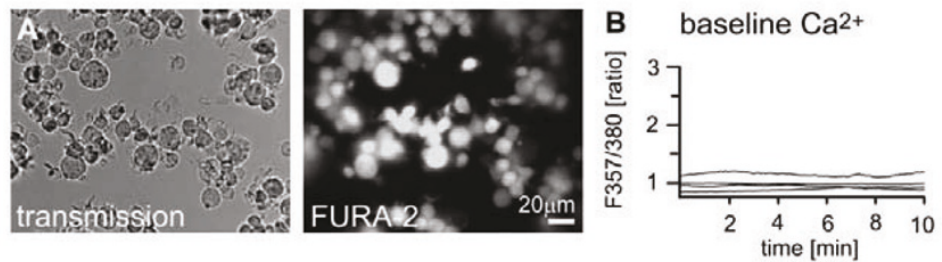

C $\mathrm{Ca}^{2+}+$ fluctuations upon treatment with particles

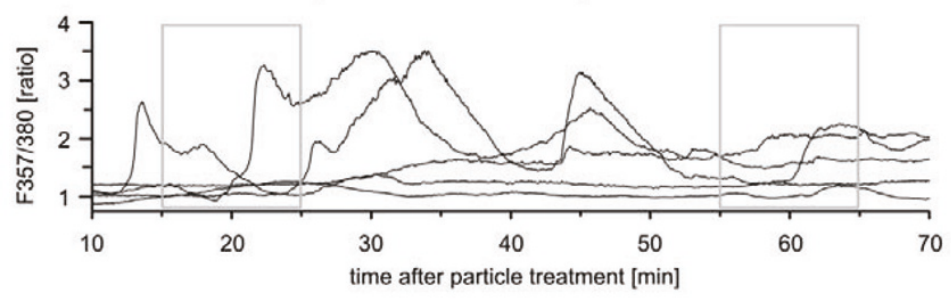

D quantitative analysis of $\mathrm{Ca}^{2}+$ fluctuations
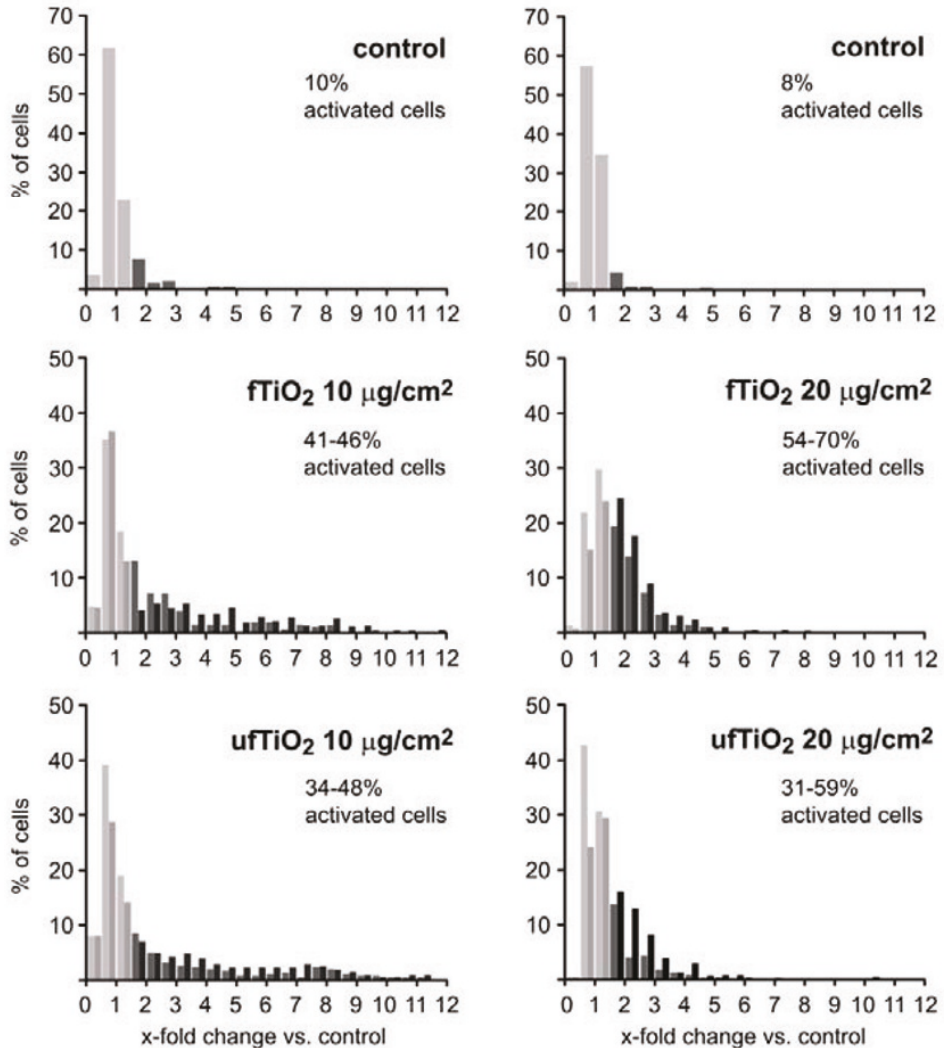

cells within s.d.: $=20 \mathrm{~min}=60 \mathrm{~min} ;$ activated cells: $=20 \mathrm{~min}=60 \mathrm{~min}$

Figure 4 Increase of $\left[\mathrm{Ca}^{2+}\right]_{i}$ after exposure of NR8383 cells to $\mathrm{TiO}_{2}$ samples. (A) Transmission image of AM (left) and image of Fura-2 fluorescence (excitation at $357 \mathrm{~nm}$ ) (right). (B) Control experiments showing Fura-2 fluorescence ratio of untreated AM. (C) Calcium fluctuations in individual cells in response to particle application (uf $\mathrm{TiO}_{2} 20 \mathrm{\mu g} / \mathrm{cm}^{2}$ ) over time. Some cells exhibit large calcium fluctuations, while others do not respond. Grey boxes indicate the time windows for which quantitative analysis shown in D was performed. (D) Quantitative analysis of calcium fluctuations: The integral of ratio traces was calculated for 10 min time windows for each individual cell. The resulting integral values were normalized to the mean of control values obtained in the absence of particles. Histograms show the percentage of cells exhibiting a 1.5 to 12 fold increase in calcium ratio integrals relative to controls. Light gray columns represent integral values within the standard deviation of controls. Dark columns represent signals of activated cells. Data are from 57 experiments on 39 coverslips, number of cells for each group: $\mathrm{n}=$ $198-443$ 


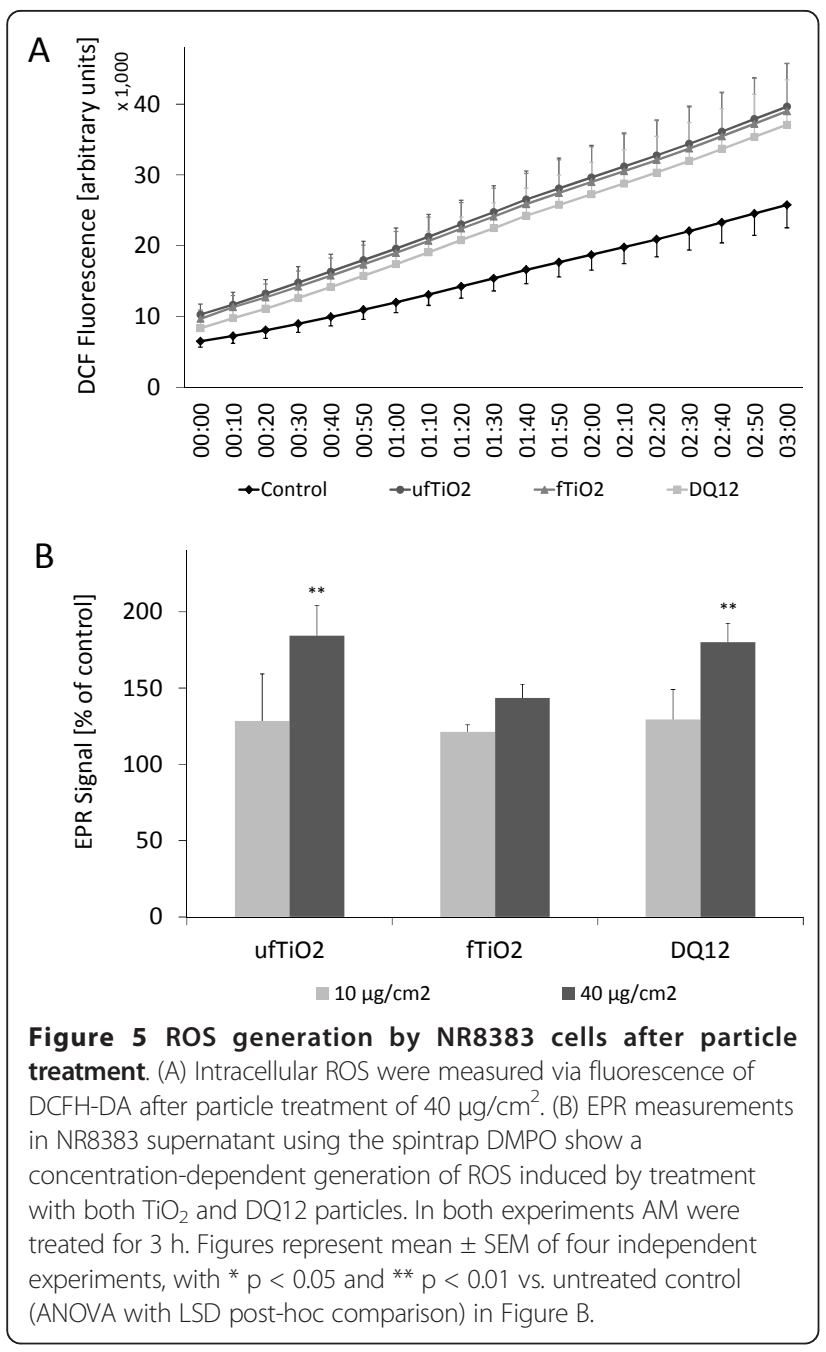

of the $\mathrm{ufTiO}_{2}$ to induce HO-1 mRNA expression was markedly impaired (8A versus $8 \mathrm{~B}$ ), whereas its effect on iNOS remained significant ( $8 \mathrm{C}$ versus $8 \mathrm{D}$ ). In contrast, DQ12 in HBSS was able to induce the expression of both genes (B and D). The $\mathrm{fTiO}_{2}$ particles showed no notable effect on the mRNA expression of either gene.

\section{Determination of specific internalization routes for the investigated particles}

In order to investigate internalization pathways for the different particle types in NR8383 cells, various approaches were used. Passive translocation was addressed by comparative evaluation of uptake at temperatures of $37^{\circ} \mathrm{C}$ and $4^{\circ} \mathrm{C}$. Results of these measurements are shown in Figure 9A. Irrespective of their size, approximately $50 \%$ of the $\mathrm{TiO}_{2}$ particles entered the cell by non-active routes, whereas for DQ12 particles a lower percentage was detected. However, it is important to note that the increased granularity of NR8383 cells at $4^{\circ} \mathrm{C}$ may also - at least partially - reflect a fraction of particles that was not internalized but merely adherent to the cells.

For the evaluation of specific mechanisms of active uptake a set of specific inhibitors was used. Comparison of the FACS analysis data at 1 and $3 \mathrm{~h}$ shows that the majority of particle uptake takes place within the first hour after particle treatment (Figure 2A-C). Hence, the particle treatment time for the inhibition experiments was set to $1 \mathrm{~h}$ (Figure 9B-D). Inhibition of actin-dependent phagocytosis and macropinocytosis using CytD reduced the uptake of $\mathrm{fTiO}_{2}$ and $\mathrm{DQ} 12$ particles, but not of $\mathrm{ufTiO}_{2}$ particles. Whereas inhibition of actin in NR8383 cells was able to abrogate active DQ12 uptake, internalization of $\mathrm{fTiO}_{2}$ could not be blocked completely via this mechanism. The uptake of $\mathrm{fTiO}_{2}$ and DQ12 particles was significantly reduced at a particle concentration $\leq 20 \mu \mathrm{g} / \mathrm{cm}^{2}$ upon inhibition of the formation of $\mathrm{CCP}$ by Chl. Inhibition of CPP-mediated internalization of $\mathrm{ufTiO}_{2}$ particles was only significant at the highest concentration tested. In contrast to these findings, treatment of NR8383 cells with an antibody against the phagocytosis receptor Fc $\gamma \mathrm{II}$ had a strong influence on the uptake of ufTiO $\mathrm{Tit}_{2}$ but of $\mathrm{fTiO}_{2}$ particles. To inhibit the formation of caveolae, the inhibitor filipin III was used. However, these experiments did not demonstrate any effect on particle uptake (data not shown). Independent experiments revealed that the filipin III concentration used could reduce uptake of the fluorescent dye Alexa555-Cholera Toxin B-subunit (CTB) by the NR8383 cells. Since CTB is known to be endocytosed through lipid rafts $[38,39]$ it is unlikely that caveolaemediated endocytosis does play a significant role in the uptake of any of the tested particles in the NR8383 cells. No significant effects on particle uptake were observed upon treatment of the cells with the vehicle control DMSO as well as with the IgG control that was used for the FcyRII antibody treatment experiments.

\section{Discussion}

In various studies ufTiO ${ }_{2}$ particles have been shown to possess increased inflammogenic potential in comparison to $\mathrm{fTiO}_{2}[2,8,40,41]$. Physiologic and systemic reactions towards NP exposure, including the uf $\mathrm{TiO}_{2}$ that was used in this study, have been shown in several in vivo investigations $[6,9,42,43]$. However, for the investigation of underlying basic cellular mechanisms and pathways, in vitro studies are necessary with established cell lines, e.g. NR8383 cells [19]. Responses of these cells to various toxicants such as PMA, endotoxin and DQ12 were shown to be highly comparable to those in primary AM obtained from rat lungs by bronchoalveolar lavage [44,45].

In the present study we observed a rapid internalization of $\mathrm{fTiO}_{2}, \mathrm{ufTiO}_{2}$ and DQ12 by AM in a clear 

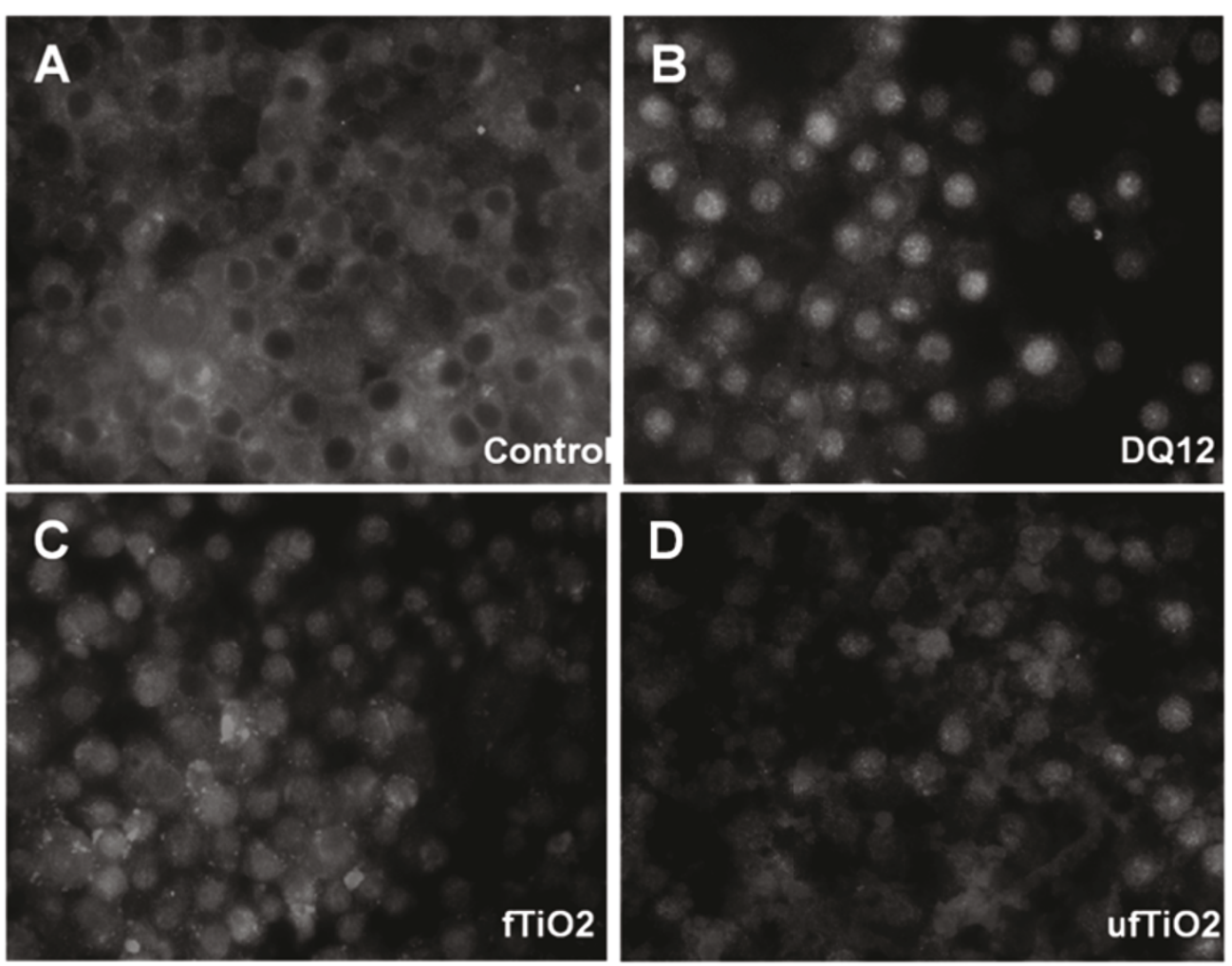

Figure $\mathbf{6}$ Induction of $\mathbf{N F} \kappa \mathbf{B}$ signaling after particle treatment. NR8383 cells were treated with particles as indicated in concentrations of 40 $\mathrm{\mu g} / \mathrm{cm}^{2}$ for $1 \mathrm{~h}$. Compared to (A) untreated AM, (B) DQ12-treated cells show the strongest nuclear staining, while (C) $\mathrm{fTiO}_{2}$ and (D) ufTiO particles demonstrate a lower nuclear staining. Original magnification: 400-fold (Zeiss Axio Observer.D1).

dose-dependent manner. Direct comparison between the specific particles was not possible, because of intrinsic differences in their light scattering properties as observed under cell free testing conditions. However, our study demonstrates that, although all three particle types are taken up, the cellular responses of the AM are substantially different. DQ12 and $\mathrm{ufTiO}_{2}$ showed similar cytotoxicity, while significant effects for $\mathrm{fTiO}_{2}$ were absent. This confirms the accepted view in particle toxicology that uptake of inorganic poorly soluble particles does not necessarily culminate in a toxic response in AM. Our findings also show that particle uptake per se does not dictate oxidative stress and the induction of inflammatory mediators. DQ12 represented the most potent sample in inducing NF- $\kappa \mathrm{B}$ activation and release of TNF- $\alpha$ and IL- $1 \beta$ from the AM. HO- 1 and iNOS mRNA expression levels in AM were most pronounced after treatment with ufTiO $\mathrm{T}_{2}$. Remarkably also, both DQ12 and $\mathrm{ufTiO}_{2}$ triggered TNF- $\alpha$ release, while only DQ12 induced IL-1 $\beta$ release.

The contrasting abilities of DQ12, ufTiO 2 and $\mathrm{fTiO}_{2}$ to induce IL- $1 \beta$ and/or TNF- $\alpha$ release can likely be explained by underlying differences in signaling pathways of activation of both inflammatory genes. NF- $\kappa \mathrm{B}$, a key regulator in the pathogenesis of particle-induced diseases $[15,46]$, controls the expression of cytokines, growth factors and distinct enzymes in response to ligation of many receptors involved in immunity [47]. Indeed, in our current study, an association between TNF- $\alpha$ levels in the supernatants from AM upon particle treatment at equal mass (i.e. DQ12 $>\mathrm{ufTiO}_{2}>$ $\mathrm{fTiO}_{2}$ ) and their abilities to cause NF- $\kappa \mathrm{B}$ p 65 nuclear translocation was found. The exclusive effect of DQ12 on IL- $1 \beta$ release is likely to be explained by the recently unraveled mechanism of its cellular activation via the inflammasome. IL- $1 \beta$ is produced as the inactive cytoplasmic precursor proIL- $1 \beta$ which has to be cleaved by caspase- 1 to generate the mature active form of the protein [48-50]. In turn, caspase-1 is regulated by the inflammasome protein complex NALP3 [51], which has been proposed to be activated by crystalline silica particles following lysosomal rupture [52] or by NADPH oxidase-generated ROS driven by phagocytosis [53]. A recent study has revealed that upon priming with LPS (to induce proIL-1 $\beta$ ), both DQ12 and $\mathrm{ufTiO}_{2}$ trigger IL$1 \beta$ secretion from bone marrow derived dendritic cells from wild-type but not caspase-1 or NLRP3-deficient mice [54]. This suggests that the contrasting IL-1 $\beta$ 


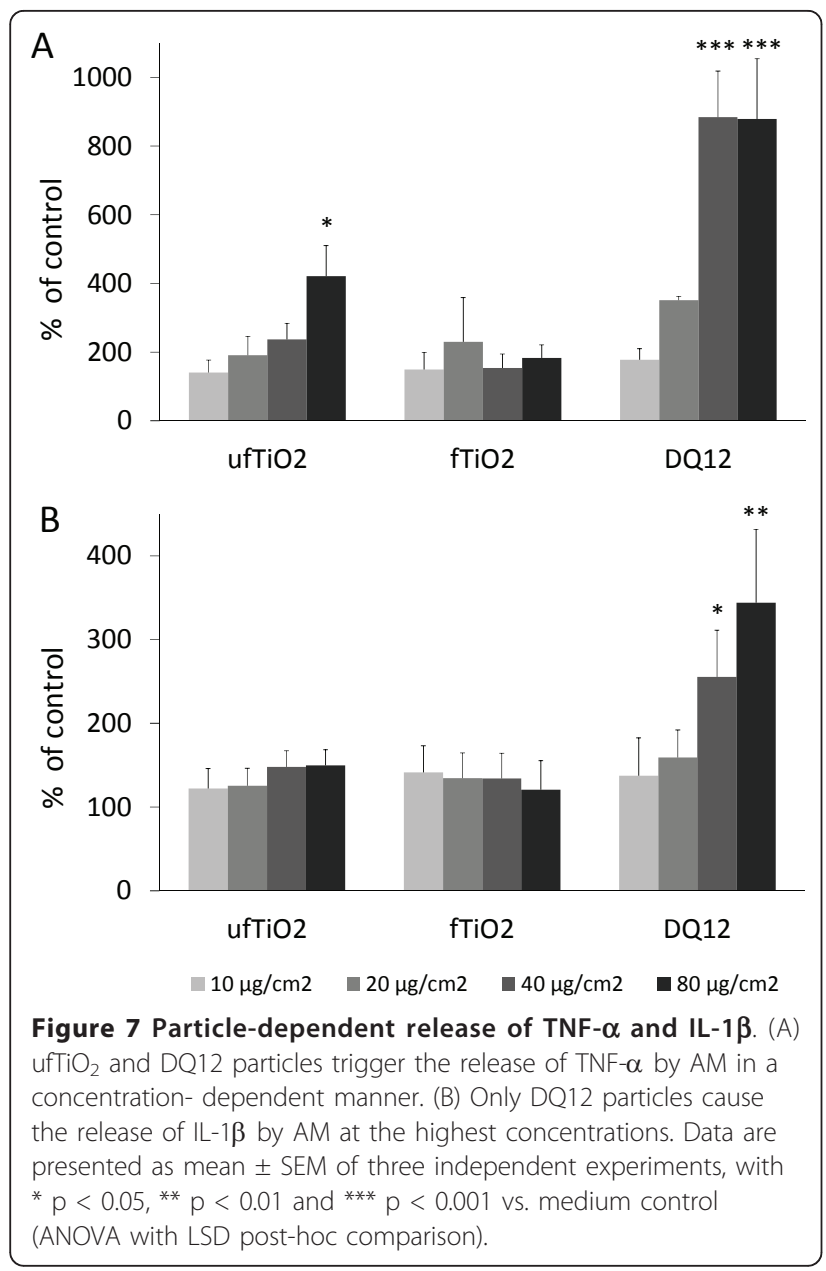

responses observed with NR8383 cells may be due to differences in the abilities of specific types of poorly soluble particles to act on proIL-1 $\beta$ activation, i.e. upstream of the inflammasome activation.

A further remarkable observation in our study concerned the mRNA expression of HO-1 and iNOS. The positive control DQ12 appeared to be less potent than $\mathrm{ufTiO}_{2}$ with regard to the induction of mRNA expression of both genes. HO-1 is considered as a sensitive marker of oxidative stress and has shown to be induced by inhaled ambient ultrafine particles [55] as well as by DQ12 quartz $[45,56]$. The induction of iNOS in macrophages has been well-established in previous studies for crystalline silica particles, and this is considered to play a major role in its pulmonary toxicity [57]. The contrasts in nuclear translocation of NF- $\kappa \mathrm{Bp} 65$, iNOS and HO-1 mRNA expression in NR8383 cells in response to $\mathrm{ufTiO}_{2}$ and DQ12 suggest that particle-induced iNOS activation in AM can occur in an NF- $\kappa \mathrm{B}$-independent manner. Thus, while ufTiO ${ }_{2}$ and $\mathrm{DQ} 12$ both trigger pro-inflammatory effects unlike $\mathrm{fTiO}_{2}$, these particles likely activate AM through different mechanisms.
In our present study, calcium influx and intracellular ROS generation were observed in AM with all three particle types to a similar extent, although both are considered as key mechanisms for adverse particle effects [58]. Tian and colleagues [59] recently demonstrated that $\mathrm{ROS}$ do not modulate $\left[\mathrm{Ca}^{2+}\right]_{\mathrm{i}}$ in quartz-treated rat $\mathrm{AM}$, however, calcium increase in the cytoplasm causes ROS generation after silica treatment. Enhanced $\left[\mathrm{Ca}^{2+}\right]_{\mathrm{i}}$ in relation to pro-inflammatory signaling pathways has also been observed after treatment of macrophages with ultrafine carbon black (CB) particles in contrast to fine $\mathrm{CB}$ [27]. To the best of our knowledge, a comparison of effects between $\mathrm{fTiO}_{2}$ and $\mathrm{ufTiO}_{2}$ on calcium homeostasis in macrophages has not yet been performed. We observed no clear difference between both particle types in terms of the number of activated cells or the intensity of activation. In line with this, intracellular ROS levels also did not differ after treatment with both types of $\mathrm{TiO}_{2}$. Our findings are in contrast to observations with $\mathrm{CB}$ [27] and suggest that particle size- and/or surface area-dependent effects on calcium influx and ROS formation are (nano)particle type-specific.

Besides intracellular ROS by DCFH-DA assay, we also determined extracellular ROS levels by means of EPR. Significant increases were observed after treatment with DQ12 and $\mathrm{ufTiO}_{2}$, but not after $\mathrm{fTiO}_{2}$. Previous studies indicate that $\mathrm{fTiO}_{2}$ and $\mathrm{ufTiO}{ }_{2}$ samples do not markedly differ in their intrinsic ROS generating capacity, when measured in cell free assays in the absence of photosensitization $[8,60,61]$. In concordance with our current findings in NR8383 cells, we could previously also show that uf $\mathrm{TiO}_{2}$, unlike $\mathrm{fTiO}_{2}$, caused enhanced ROS formation in supernatants of A549 human lung epithelial cells. This suggests that ROS predominantly originate from interactions between $\mathrm{ufTiO}_{2}$ and cellular constituents and compartments rather than from the particles themselves. Potential relevant sources herein include NADPH oxidase enzyme family members as well as mitochondria [8]. Our findings indicate that different ROS-generating mechanisms exist in AM, with a selective sensitivity towards particle size or chemical composition as already concluded by Dick and colleagues [62]. At this stage however, it should be emphasized that the calcium imaging experiments and both ROS assays were not performed in complete culture medium, but in saline, or $\mathrm{HBSS}^{+/+}$, respectively. This was required to minimize potent radical scavenging properties of various (protein) constituents in the FCScontaining medium that can interfere with the assays. DLS measurements on unfiltered samples demonstrated that both $\mathrm{fTiO}_{2}$ and $\mathrm{ufTiO}_{2}$, when suspended in HBSS, reside as large agglomerates with an average hydrodynamic diameter of 936.6 or $2018 \mathrm{~nm}$, respectively, unlike in FCS-containing medium (see Table 1). Lacking 
differences in calcium influx and intracellular ROS between $\mathrm{fTiO}_{2}$ and $\mathrm{ufTiO} \mathrm{T}_{2}$ may therefore reflect an "agglomeration"-response of NR8383 cells. Interestingly though, increased extracellular ROS levels could be shown for ufTiO ${ }_{2}$ by EPR analysis, despite its agglomeration. All other parameters in our study were evaluated using FCS-containing culture medium, in which the number-average diameter of $\mathrm{ufTiO}_{2}$ sample was well within the nanosize range. However, apart from effects on agglomeration behavior, these treatment conditions also generate so-called (protein) coronas, most probably in a material specific manner [63]. This should be taken into account with regard to the various effects described in our study.

The importance of agglomeration and (protein) coating effects can be demonstrated from the comparative mRNA expression measurement of $\mathrm{HO}-1$ and iNOS in HBSS treated versus full medium treated NR8383 cells (Figure 8). When suspended in $\mathrm{HBSS}, \mathrm{ufTiO}_{2}$ failed to cause a significant increase of HO-1 mRNA, which indicated that the agglomeration state (see Table 1) of this sample is crucial for its ability to induce this oxidative stress marker. Remarkably however, the induction of iNOS by $\mathrm{ufTiO}_{2}$ was not abrogated. This suggests that the activation of $\mathrm{HO}-1$ and iNOS by particles involves, at least in part, different signaling pathways driven by different physico-chemical properties. In contrast to the ultrafine $\mathrm{TiO}_{2}$, the crystalline silica sample induced $\mathrm{HO}-1$ and iNOS under both treatment conditions. At the lower treatment concentration $(10 \mu \mathrm{g} /$ $\mathrm{cm}^{2}$ ), the effect of DQ12 tended to be even stronger in the HBSS than in the FCS-containing medium. Current observations are in concordance with previous investigations in our laboratory where chemical coating of DQ12 was shown to abrogate its pro-inflammatory properties in NR8383 cells $[45,64]$, as well as in vivo in the rat lung [32].

The goal of our study was to investigate the interactions between particles and AM and their associated pro-inflammatory effects in relation to particle size and

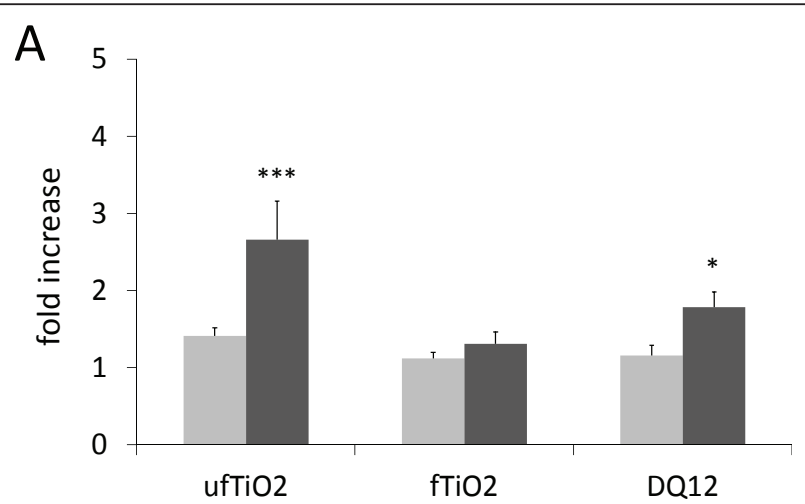

$\mathrm{B}_{5}$
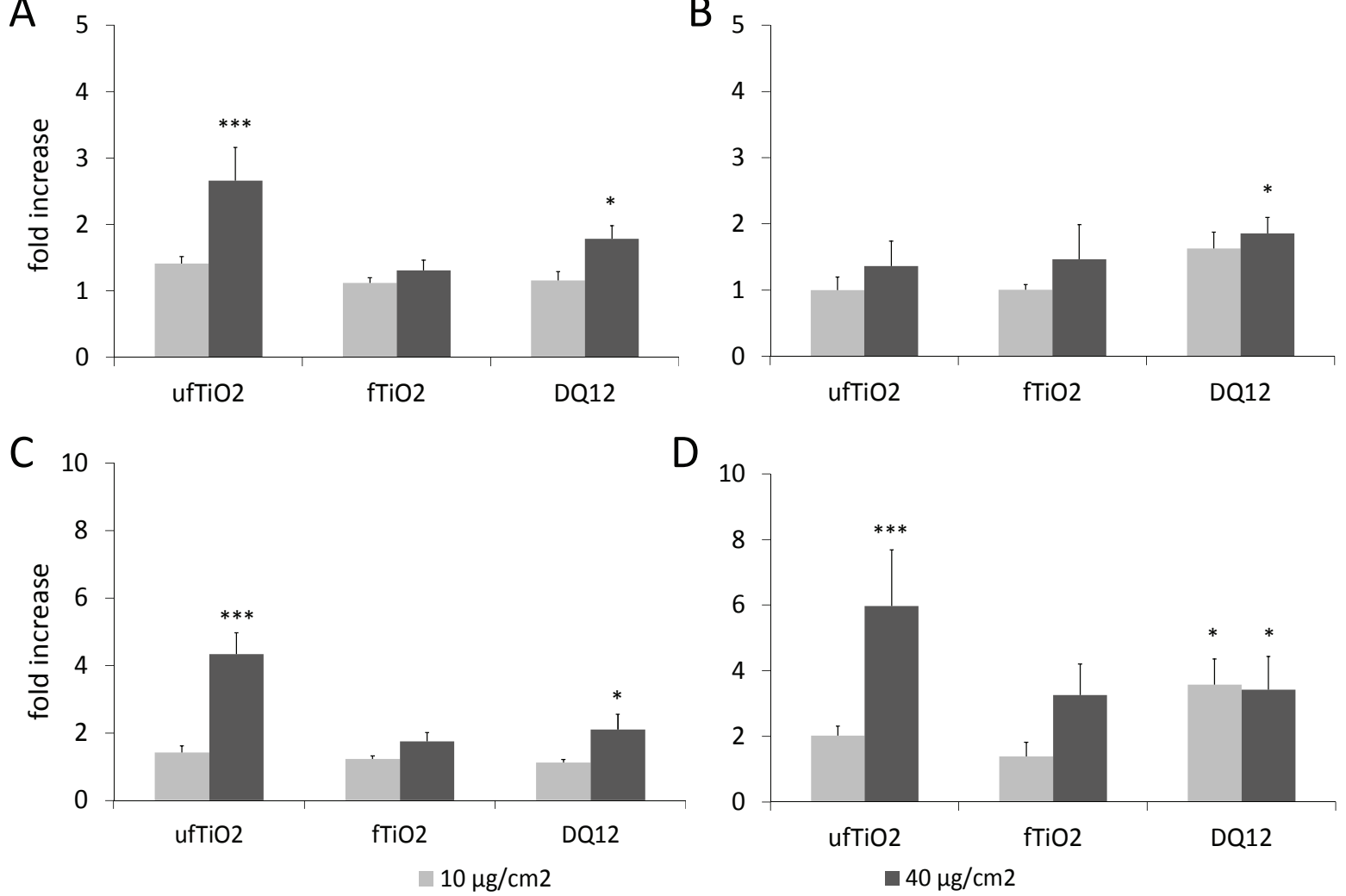

10

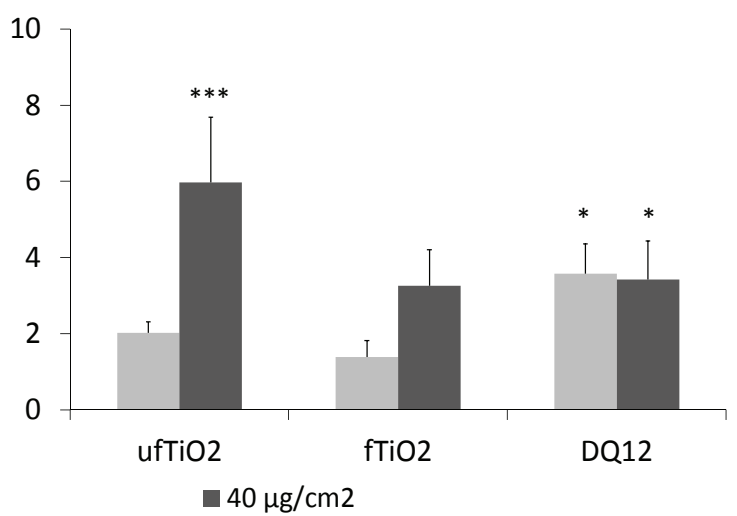

Figure 8 Particle-dependent impact on the mRNA regulation of HO-1 and iNOS. NR8383 cells were treated with $10 \mathrm{or} 40 \mu \mathrm{g} / \mathrm{cm}^{2}$ of the indicated particles for $4 \mathrm{~h}$ in complete culture medium ( $\mathrm{A}$ and $\mathrm{C}$ ) or $\mathrm{HBSS}$ ( $\mathrm{B}$ and $\mathrm{D}$ ). In medium ( $\mathrm{A}$ ), ufTiO $\mathrm{O}_{2}$ and DQ12 trigger mRNA upregulation of the stress-response gene $\mathrm{HO}-1$ in a concentration-dependent manner, whereas in $\mathrm{HBSS}$ (B) a significant induction was only observed with DQ12. The synthesis of the inflammatory marker iNOS is induced on the mRNA level by both ufTiO 2 and $\mathrm{DQ}_{12}$ at a concentration of $40 \mathrm{\mu g} / \mathrm{cm}^{2}$ in medium (C) as well as in HBSS (D). In HBSS, DQ12 also elicited significant induction of iNOS at the lower treatment concentration. All data are corrected for GAPDH. Figures represent mean \pm SEM of seven $(A, C)$ or three $(B, D)$ independent experiments, with * $p<0.05,{ }^{* *} p<0.01$ and ${ }^{* * *} p<0.001$ vs. medium control (ANOVA with LSD post-hoc comparison). 


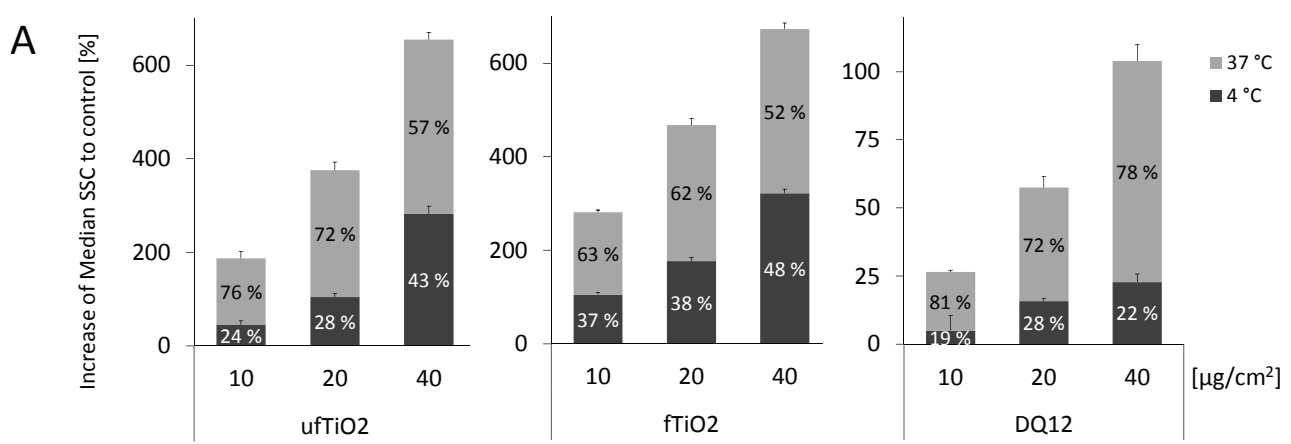

B

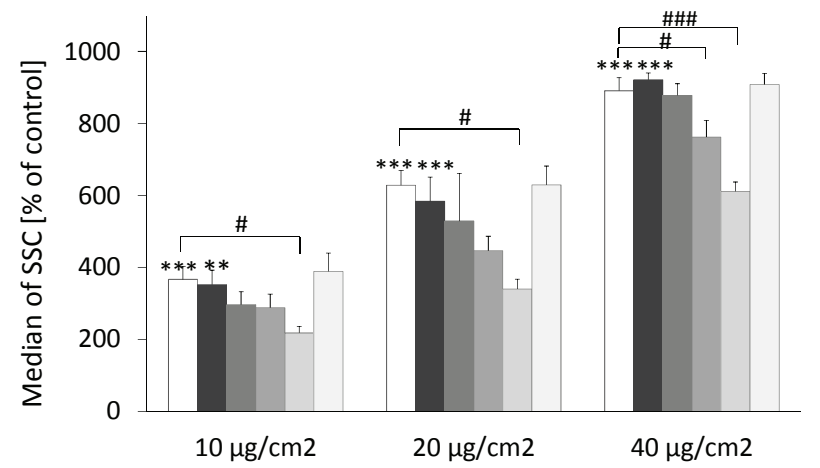

C

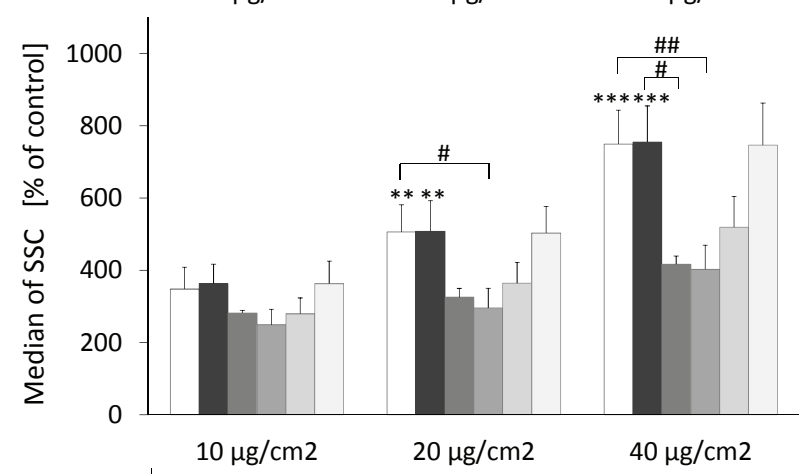

D

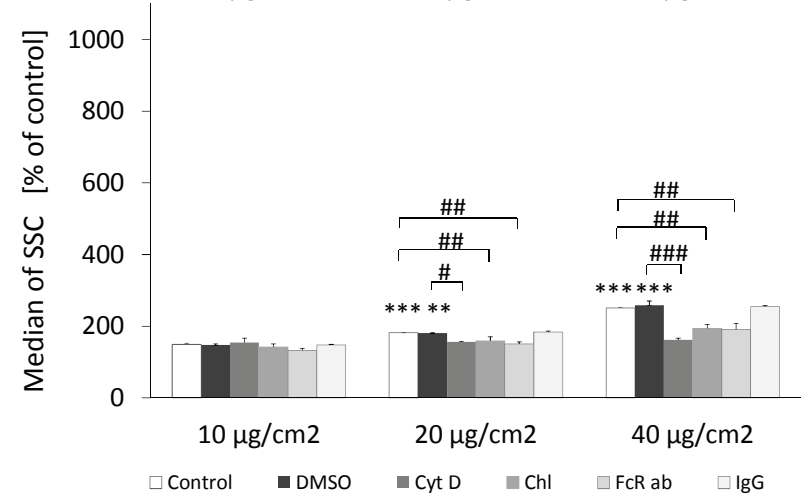

Figure 9 Particle-specific mechanisms of internalization. (A) Assessment of the percentage of passively entered particles by measuring at $4^{\circ}$ C. The results are depicted as increase of SSC median compared to untreated NR8383 cells. (B - D) Preincubation for 30 min with cytochalasin D (CytD), chlorpromazine (Chl) or an antibody against FcyRll ( $F C R$ ab) in order to block active uptake mechanisms, i.e. actin cytoskeleton-dependent uptake, uptake via CCP formation and FcyRll-mediated internalization, respectively. Treatment with (B) $\mathrm{ufTiO}_{2}$, (C) $\mathrm{fTiO}_{2}$ or (D) DQ12 particles in concentrations of 10,20 or $40 \mathrm{\mu g} / \mathrm{cm}^{2}$ for $1 \mathrm{~h}$ shows particle-specific internalization routes. Figures represent median \pm SEM as percentage of untreated or vehicle (DMSO) control cells of three independent experiments, with * $p<0.05,{ }^{* *} p<0.01$ and ${ }^{* * *} p<0.001$ (ANOVA with Dunnett post-hoc comparison); as well as \# $p<0.05$, \#\# $p<0.01$ and \#\#\# $p<0.001$ for reduced granularity vs. appropriate particle treated cells (ANOVA with LSD post-hoc comparison), respectively. 
physico-chemical properties. The contrasting cellular responses observed by the three types of particles could not be explained by uptake by the AM per se. Therefore, investigations were performed addressing the underlying cellular mechanisms of particle internalization. Herein, the importance of particle size and distribution as well as of agglomeration behavior in cell culture medium suspensions was taken into account. We also specifically compared the uptake mechanisms for both $\mathrm{TiO}_{2}$ samples with those that we previously investigated for DQ12 in NR8383 cells $[20,65]$. Evaluation of uptake at $4^{\circ} \mathrm{C}$ indicates a passive, energy-independent entrance of particles into cells and/or their adherence to outer membranes of AM. For both $\mathrm{TiO}_{2}$ samples the proportion was found to be higher than for DQ12. However, no clear difference could be seen between $\mathrm{fTiO}_{2}$ and ufTiO ${ }_{2}$ despite the marked differences in their size distributions in complete culture medium used for the uptake experiments. These observations are in line with previous findings for both materials concerning their uptake into A549 human lung epithelial cells [8].

A series of specific inhibition experiments were performed to investigate the various active uptake routes in NR8383 cells. A combination between different uptake mechanisms in our study can be reasoned by the findings of Rothen-Rutishauser and colleagues [66] showing $\mathrm{TiO}_{2}$ particles in a three-dimensional cell culture model free in the cytoplasm as well as membrane-bound. Our own findings indicate that the active internalization of $\mathrm{ufTiO}_{2}$ particles in AM is mainly performed via a Fc $\gamma$ RII-mediated mechanism and, to a lesser extent, by CCP which exhibit a vesicle diameter of $100-120 \mathrm{~nm}$ [67]. Uptake of $\mathrm{fTiO}_{2}$ particles also took place via CCP, but in addition an actin-dependent uptake mechanism was equally involved. This may include macropinocytosis, by which large vesicles between $0.2-10 \mu \mathrm{m}$ are formed spontaneously or upon stimulation [68]. Actinmediated endocytosis is connected to receptor activation like MARCO and SR-A mediated processes, as previously shown by Kobzik and co-workers for primary AM of different species [69-71]. The prominent receptor-mediated uptake mechanism for $\mathrm{fTiO}_{2}$ and silica by human macrophages via SR-A reported by Thakur et al. [24] is beyond all question for our study, since NR8383 cells lack this receptor as determined by PCR analysis (data not shown). As expected from their size distribution, the DQ12 particles were taken up by actin-dependent classical phagocytosis which is described to be mediated by Fc $\gamma$ RII [65]. Phagocytosis is the most effective clearance mechanism for particles between 1 - 5 $\mu \mathrm{m}$ in diameter [67]. Inhibition experiments with filipin III were found to be unsuccessful in reducing particle uptake in NR8383 cells. For DQ12 and $\mathrm{fTiO}_{2}$ this could be anticipated in view of their size distributions and the typical diameter of $50-100 \mathrm{~nm}$ of the caveolae vesicles. However, filipin III was also ineffective for $\mathrm{ufTiO}_{2}$, despite the fact that its number-average hydrodynamic diameter falls into the vesicle size range of caveolae. This suggests that even for these smaller particles/aggregates alternative uptake pathways such as CCP dominate. Notably, apart from differences in primary particle size and agglomeration behavior, both $\mathrm{TiO}_{2}$ samples also differ in their chemical composition. Therefore, a potential role of rutile vs. anatase in particle-macrophage interactions can not be ruled out. Another explanation may be related to the specific method of particle uptake used in the present study. In relation to the relative contribution of particle number and particle mass to changes in AM granularity it is possible that the uptake of the smallest particles is underestimated in the flow cytometry approach. However, in a recent study it was demonstrated that flow cytometry can detect organosilica nanoparticles as small as $58 \mathrm{~nm}$ in diameter via side scattering analysis and that the method is actually suitable for size distribution analysis [72]. Comparison of the TEM distribution data of the samples used in our study with SSC histograms of cell free particle suspensions obtained with the same apparatus (FACS Calibur) indicates that this is also valid for $\mathrm{TiO}_{2}$ (data not shown).

A major conclusion that can be drawn from the uptake experiments is that $\mathrm{fTiO}_{2}$ and DQ12 which are both classified as "fine" particles show a specificity and size-dependency with regard to the tested cellular uptake mechanisms. Further studies are needed to investigate these alternative uptake pathways using independent inhibition strategies (e.g. siRNA). Because of the limitations of the cell line used in our present study (e. g. lack of SR), this should be done preferably with primary macrophages. These studies should also focus on the potential contribution of particle-specific coronas to kinetics and pathways of uptake and associated cellular responses.

Our observation that multiple uptake mechanisms may be relevant for one specific type of particle can be explained by the size-distribution of the specific samples and, likely of more importance, their agglomeration behavior when suspended in culture media. Obviously, for the identification of the in vivo relevant mechanisms of uptake of specific types of (nano)particles by AM, one should obviously take into account the role of the micro-environment of these cells, e.g. potential coronaforming constituents of the alveolar lining fluid. Nevertheless, our current in vitro findings emphasize on the aspect that the inflammatory properties are not driven by uptake per se. It appeared that specific physico-chemical properties of quartz, $\mathrm{fTiO}_{2}$ and $\mathrm{ufTiO}_{2}$ particles are responsible for qualitative as well as quantitative 
differences in their ability to induce oxidative stress and inflammatory responses in AM. In contrast to $\mathrm{fTiO}_{2}$ which was relatively inert, both DQ12 and $\mathrm{ufTiO}_{2}$ increased extracellular ROS and TNF- $\alpha$ release, while uf $\mathrm{TiO}_{2}$ predominantly enhanced iNOS mRNA expression, and DQ12 exclusively triggered IL- $1 \beta$ release. Our findings indicate that these dissimilar macrophage responses may be related to specific differences in uptake mechanisms, respectively involving actin cytoskeleton, CCP formation and Fc $\gamma$ RII-mediated internalization. The findings with $\mathrm{fTiO}_{2}$ demonstrate that actin and $\mathrm{CCP}$ are not necessarily involved in pro-inflammatory cytokine release and extracellular ROS generation by macrophages after particle uptake. The data for DQ12 and ufTiO ${ }_{2}$ indicate a role for Fc $\gamma$ RII in macrophage responsiveness. The contrasting activation profiles for both materials emphasize the need for further investigations, specifically regarding the inflammasome. The relative overlap of the investigated mechanisms for the various types of particles used in this study are likely explained by their size distributions. Indeed, studies with monodisperse particles are most appropriate to clarify individual mechanisms of uptake by macrophages. However, it should be emphasized that AM typically encounter size ranges of particles and their agglomerates of various types of respirable materials, including the fine and ultrafine $\mathrm{TiO}_{2}$ samples used in our current study.

\section{List of abbreviations used}

AM: alveolar macrophages; ANOVA: analysis of variance; AP-1: activator protein $1 ;\left[\mathrm{Ca}^{2+}\right]_{i}$ : intracellular calcium concentration; CB: carbon black; CCP: clathrin coated pits; Chl: chlorpromazine; CytD: cytochalasin D; DCFH-DA: dichlorodihydrofluorescein diacetate; DF-LSM: dark field light scattering microscopy; DLS: dynamic light scattering; DMPO: 5;5-dimethyl-1-pyrroline-Noxide; DMSO: dimethyl sulphoxide; DQ12 quartz: Dörentruper quartz; EA: Elemental analysis; EPR: Electron Paramagnetic Resonance; FCS: fetal calf serum; FcyRll: FCy receptor II; FSC: forward scatter; $\mathrm{fTiO}_{2}$ : fine titanium dioxide; GAPDH: Glycerinaldehyd-3-phosphat-Dehydrogenase; HBSS: Hank's buffered saline solution; HO-1: heme oxygenase 1; IgG1 K: Immunoglobulin G1; kappa chain; IL-1 $\beta$ : interleukin 1 $\beta$; iNOS: inducible nitric oxide synthase; LPS: lipopolysaccaride; MARCO: Macrophage receptor with collagenous structure; NADPH: nicotinamide adenine dinucleotide phosphate; NALP3: NACHT; LRR and PYD domains-containing protein 3; NF-KB: nuclear factor kappa B; NLRP: NOD-like receptor family; NP: nanoparticles; PBS: phosphate buffered saline; PKC: protein kinase C; PLC: Phospholipase C; PMA: phorbol 12-myristate 13-acetate; ROls: regions of interest; ROS: reactive oxygen species; SSA: specific surface area; SSC: sideward scatter; TEM: transmission electron microscopy; TGA: thermogravimetric analysis; TNF-a: tumor necrosis factor alpha; ufTiO ${ }_{2}$ : ultrafine titanium dioxide; WST-1: water-soluble tetrazolium.

\section{Acknowledgements}

We are grateful to Christel Weishaupt (IUF) for technical assistance. Furthermore, we thank Claudia Roderigo (Heinrich-Heine-University Düsseldorf) for performing the calcium imaging experiments and Dr. Lhoussaine Belkoura (University of Cologne) for the performance of TEM analysis.

The current address of P.H. is the Division of Cardiology, University of Louisville, USA.
This work was financially supported by the Federal Ministry of the Environment (BMU) as well as by the Graduate School GRK1427 of the German Research Council (DFG).

\section{Author details}

${ }^{1}$ IUF - Leibniz Research Institute for Environmental Medicine, Düsseldorf, Germany. ${ }^{2}$ Institute for Neurobiology, Heinrich-Heine-University Düsseldorf, Germany. Institute of Physical Chemistry, University of Cologne, Cologne, Germany. ${ }^{4}$ Department of Health Risk Analysis and Toxicology, Maastricht University, Maastricht, The Netherlands.

\section{Authors' contributions}

AMS performed most of the experimental work and drafted the manuscript. $J \mathrm{~L}$ analyzed the calcium imaging experiments. $A B$ performed the particle characterization experiments. DvB performed the GRT-PCR experiments, PH prepared light microscopic data. FJvS was involved in the design of mRNA experiments. AMS was involved in the design and analysis of the particle characterization experiments as well as helped drafting the manuscript. CRR was involved in the design and analysis of the calcium imaging experiments as well as helped drafting the manuscript. RPFS was involved in the study design, statistical analysis and helped drafting the manuscript. CA was involved in the study design and coordination and helped drafting the manuscript. All authors read, commented on and approved the manuscript.

\section{Competing interests}

The authors declare that they have no competing interests.

Received: 21 December 2010 Accepted: 13 October 2011

Published: 13 October 2011

\section{References}

1. Stone V, Johnston H, Schins RP: Development of in vitro systems for nanotoxicology: methodological considerations. Crit Rev Toxicol 2009, 39(7):613-26.

2. Oberdorster G, Oberdorster E, Oberdorster J: Nanotoxicology: an emerging discipline evolving from studies of ultrafine particles. Environ Health Perspect 2005, 113(7):823-39.

3. Krug HF, Wick P: Nanotoxicology: An Interdisciplinary Challenge. Angewandte Chemie (International ed) 2011, 50:1260-78.

4. Nel A, Xia T, Madler L, Li N: Toxic potential of materials at the nanolevel. Science 2006, 311(5761):622-7.

5. Shvedova AA, Castranova V, Kisin ER, Schwegler-Berry D, Murray AR, Gandelsman VZ, Maynard A, Baron P: Exposure to carbon nanotube material: assessment of nanotube cytotoxicity using human keratinocyte cells. J Toxicol Environ Health A 2003, 66(20):1909-26.

6. Oberdorster G: Pulmonary effects of inhaled ultrafine particles. Int Arch Occup Environ Health 2001, 74(1):1-8.

7. Stoeger T, Reinhard C, Takenaka S, Schroeppel A, Karg E, Ritter B, Heyder J, Schulz H: Instillation of six different ultrafine carbon particles indicates a surface area threshold dose for acute lung inflammation in mice. Environ Health Perspect 2006, 114(3):328-33.

8. Singh S, Shi T, Duffin R, et al: Endocytosis, oxidative stress and IL-8 expression in human lung epithelial cells upon treatment with fine and ultrafine TiO2: role of the specific surface area and of surface methylation of the particles. Toxicol Appl Pharmacol 2007, 222(2):141-51.

9. Lindenschmidt RC, Driscoll KE, Perkins MA, Higgins JM, Maurer JK, Belfiore KA: The comparison of a fibrogenic and two nonfibrogenic dusts by bronchoalveolar lavage. Toxicol Appl Pharmacol 1990, 102(2):268-81.

10. Johnston $H$, Hutchison GR, Christensen FM, Peters S, Hankin S, Stone V: Identification of the mechanisms that drive the toxicity of $\mathrm{TiO}_{2}$ particulates: the contribution of physicochemical characteristic. Part Fib Tox 2010, 6:33

11. Bermudez E, Mangum JB, Wong BA, Asgharian B, Hext PM, Warheit DB, Everitt Jl: Pulmonary responses of mice, rats, and hamsters to subchronic inhalation of ultrafine titanium dioxide particles. Toxicol Sci 2004, 77(2):347-57.

12. Lardot CG, Huaux FA, Broeckaert FR, Declerck PJ, Delos M, Fubini B, Lison DF: Role of urokinase in the fibrogenic response of the lung to mineral particles. Am J Respir Crit Care Med 1998, 157(2):617-28. 
13. Kuempel ED, Attfield MD, Vallyathan V, Lapp NL, Hale JM, Smith RJ, Castranova V: Pulmonary inflammation and crystalline silica in respirable coal mine dust: dose-response. J Biosci 2003, 28(1):61-9.

14. Donaldson K, Tran CL: Inflammation caused by particles and fibers. Inhalation toxicology 2002, 14(1):5-27.

15. Rimal B, Greenberg AK, Rom WN: Basic pathogenetic mechanisms in silicosis: current understanding. Current opinion in pulmonary medicine 2005, 11(2):169-73.

16. Unfried K, Albrecht C, Klotz LO, von Mikecz A, Grether-Beck S, Schins RPF: Cellular responses to nanoparticles: Target structures and mechanisms. Nanotoxicology 2007, 1:20.

17. Warheit $\mathrm{DB}$, Reed $\mathrm{KL}$, Sayes $\mathrm{CM}$ : A role for nanoparticle surface reactivity in facilitating pulmonary toxicity and development of a base set of hazard assays as a component of nanoparticle risk management. Inhalation toxicology 2009, 21(Suppl 1):61-7.

18. Martin TR, Frevert CW: Innate immunity in the lungs. Proc Am Thorac Soc 2005, 2(5):403-11.

19. Helmke RJ, German VF, Mangos JA: A continuous alveolar macrophage cell line: comparisons with freshly derived alveolar macrophages. In Vitro Cell Dev Biol 1989, 25(1):44-8.

20. Haberzettl P, Schins RP, Hohr D, Wilhelmi V, Borm PJ, Albrecht C: Impact of the Fcgammall-receptor on quartz uptake and inflammatory response by alveolar macrophages. Am J Physiol Lung Cell Mol Physiol 2008, 294(6) L1137-48.

21. Dai $X$, Jayapal M, Tay HK, et al: Differential signal transduction, membrane trafficking, and immune effector functions mediated by FcgammaRI versus FcgammaRIla. Blood 2009, 114(2):318-27.

22. Rada B, Leto TL: Oxidative innate immune defenses by Nox/Duox family NADPH oxidases. Contrib Microbiol 2008, 15:164-87.

23. Kobzik L: Lung macrophage uptake of unopsonized environmental particulates. Role of scavenger-type receptors. J Immunol 1995, 155(1):367-76.

24. Thakur SA, Hamilton RF Jr, Holian A: Role of scavenger receptor a family in lung inflammation from exposure to environmental particles. Immunotoxicol 2008, 5(2):151-7.

25. Akagawa KS: Functional heterogeneity of colony-stimulating factorinduced human monocyte-derived macrophages. Int J Hematol 2002, 76(1):27-34

26. Schulze-Osthoff K, Los M, Baeuerle PA: Redox signalling by transcription factors NF-kappa B and AP-1 in lymphocytes. Biochem Pharmacol 1995, 50(6):735-41.

27. Brown DM, Donaldson K, Borm PJ, Schins RP, Dehnhardt M, Gilmour P, Jimenez LA, Stone V: Calcium and ROS-mediated activation of transcription factors and TNF-alpha cytokine gene expression in macrophages exposed to ultrafine particles. Am J Physiol Lung Cell Mol Physiol 2004, 286(2):L344-53.

28. Kang JL, Pack IS, Hong SM, Lee HS, Castranova V: Silica induces nuclear factor-kappa B activation through tyrosine phosphorylation of I kappa Balpha in RAW264.7 macrophages. Toxicol Appl Pharmacol 2000, 169(1):59-65.

29. Shukla A, Ramos-Nino M, Mossman B: Cell signaling and transcription factor activation by asbestos in lung injury and disease. Int J Biochem Cell Biol 2003, 35(8):1198-209.

30. Castranova V, Vallyathan V: Silicosis and coal workers' pneumoconiosis. Environ Health Perspect 2000, 108(Suppl 4):675-84.

31. Donaldson K, Stone V, Duffin R, Clouter A, Schins R, Borm P: The quartz hazard: effects of surface and matrix on inflammogenic activity. J Environ Pathol Toxicol Oncol 2001, 20(Suppl 1):109-18.

32. Albrecht C, Schins RP, Hohr D, Becker A, Shi T, Knaapen AM, Borm PJ: Inflammatory time course after quartz instillation: role of tumor necrosis factor-alpha and particle surface. American journal of respiratory cell and molecular biology 2004, 31(3):292-301.

33. Albrecht $C$, Knaapen AM, Becker A, Hohr D, Haberzettl P, van Schooten FJ, Borm PJ, Schins RP: The crucial role of particle surface reactivity in respirable quartz-induced reactive oxygen/nitrogen species formation and APE/Ref-1 induction in rat lung. Respir Res 2005, 6-129.

34. Warheit $D B$, Webb TR, Reed KL, Frerichs S, Sayes CM: Pulmonary toxicity study in rats with three forms of ultrafine-TiO2 particles: differential responses related to surface properties. Toxicology 2007, 230(1):90-104

35. Brunauer S, Emmert PH, Teller E: Adsorption of gases in multimolecular layers. J Amer Chem Soc 1938, 60:309-19.
36. Palecanda A, Kobzik L: Alveolar macrophage-environmental particle interaction: analysis by flow cytometry. Methods 2000, 21(3):241-7.

37. Livak KJ, Schmittgen TD: Analysis of relative gene expression data using real-time quantitative PCR and the 2(-Delta Delta $C(T))$ Method. Methods 2001, 25(4):402-8.

38. Auriac A, Willemetz A, Canonne-Hergaux F: Lipid raft-dependent endocytosis: a new route for hepcidin-mediated regulation of ferroportin in macrophages. Haematologica 2010, 95(8):1269-77.

39. Yacobi NR, Malmstadt N, Fazlollahi F, et al: Mechanisms of alveolar epithelial translocation of a defined population of nanoparticles. American journal of respiratory cell and molecular biology 2010, 42(5):604-14.

40. Oberdorster G, Ferin J, Lehnert BE: Correlation between particle size, in vivo particle persistence, and lung injury. Environ Health Perspect 1994 102(Suppl 5):173-9.

41. Sager TM, Castranova V: Surface area of particle administered versus mass in determining the pulmonary toxicity of ultrafine and fine carbon black: comparison to ultrafine titanium dioxide. Particle and fibre toxicology 2009, 6:15

42. Ferin J, Oberdorster G: Biological effects and toxicity assessment of titanium dioxides: anatase and rutile. Am Ind Hyg Assoc J 1985, 46(2):69-72.

43. van Ravenzwaay B, Landsiedel R, Fabian E, Burkhardt S, Strauss V, MaHock L: Comparing fate and effects of three particles of different surface properties: nano-TiO(2), pigmentary $\mathrm{TiO}(2)$ and quartz. Toxicol Lett 2009, 186(3):152-9.

44. Albrecht C, Scherbart AM, van Berlo D, Braunbarth CM, Schins RP, Scheel J: Evaluation of cytotoxic effects and oxidative stress with hydroxyapatite dispersions of different physicochemical properties in rat NR8383 cells and primary macrophages. Toxicol In Vitro 2009, 23(3):520-30.

45. van Berlo D, Knaapen AM, van Schooten FJ, Schins RP, Albrecht C: NFkappaB dependent and independent mechanisms of quartz-induced proinflammatory activation of lung epithelial cells. Part Fibre Toxicol 2010, 7:13.

46. Donaldson K, Stone V: Current hypotheses on the mechanisms of toxicity of ultrafine particles. Ann Ist Super Sanita 2003, 39(3):405-10.

47. Memet S: NF-kappaB functions in the nervous system: from development to disease. Biochem Pharmacol 2006, 72(9):1180-95.

48. Dinarello CA: Interleukin-1 beta, interleukin-18, and the interleukin-1 beta converting enzyme. Annals of the New York Academy of Sciences 1998, 856:1-11.

49. Thornberry NA, Lazebnik Y: Caspases: enemies within. Science 1998 281(5381):1312-6.

50. Agostini L, Martinon F, Burns K, McDermott MF, Hawkins PN, Tschopp J: NALP3 forms an IL-1beta-processing inflammasome with increased activity in Muckle-Wells autoinflammatory disorder. Immunity 2004, 20(3):319-25.

51. Martinon F, Tschopp J: Inflammatory caspases and inflammasomes: master switches of inflammation. Cell Death Differ 2007, 14(1):10-22.

52. Hornung $V$, Bauernfeind $F$, Halle A, Samstad EO, Kono H, Rock KL, Fitzgerald KA, Latz E: Silica crystals and aluminum salts activate the NALP3 inflammasome through phagosomal destabilization. Nat Immunol 2008, 9(8):847-56.

53. Dostert C, Petrilli V, Van Bruggen R, Steele C, Mossman BT, Tschopp J: Innate immune activation through Nalp3 inflammasome sensing of asbestos and silica. Science 2008, 320(5876):674-7.

54. Winter $M$, Beer HD, Hornung $V$, Kramer $U$, Schins RP, Forster I: Activation of the inflammasome by amorphous silica and $\mathrm{TiO}(2)$ nanoparticles in murine dendritic cells. Nanotoxicology

55. Li N, Sioutas C, Cho A, et al: Ultrafine particulate pollutants induce oxidative stress and mitochondrial damage. Environmental health perspectives 2003, 111(4):455-60.

56. Li H, van Berlo D, Shi T, Speit G, Knaapen AM, Borm PJ, Albrecht C, Schins RP: Curcumin protects against cytotoxic and inflammatory effects of quartz particles but causes oxidative DNA damage in a rat lung epithelial cell line. Toxicol Appl Pharmacol 2008, 227(1):115-24.

57. Porter DW, Millecchia L, Robinson VA, et al: Enhanced nitric oxide and reactive oxygen species production and damage after inhalation of silica. American journal of physiology 2002, 283(2):L485-93.

58. Donaldson K, Stone V, Borm PJ, et al: Oxidative stress and calcium signaling in the adverse effects of environmental particles (PM10). Free Radic Biol Med 2003, 34(11):1369-82. 
59. Tian F, Zhu T, Shang Y: Intracellular influx of calcium induced by quartz particles in alveolar macrophages. Toxicol Appl Pharmacol 2010, 242(2):173-81.

60. Jin C, Tang Y, Yang FG, Li XL, Xu S, Fan XY, Huang YY, Yang YJ: Cellular Toxicity of TiO(2) Nanoparticles in Anatase and Rutile Crystal Phase. Biol Trace Elem Res 2010.

61. Fenoglio I, Greco G, Livraghi S, Fubini B: Non-UV-induced radical reactions at the surface of $\mathrm{TiO} 2$ nanoparticles that may trigger toxic responses. Chemistry (Weinheim an der Bergstrasse, Germany) 2009, 15(18):4614-21.

62. Dick CA, Brown DM, Donaldson $\mathrm{K}$, Stone $\mathrm{V}$ : The role of free radicals in the toxic and inflammatory effects of four different ultrafine particle types. Inhalation toxicology 2003, 15(1):39-52.

63. Monopoli MP, Bombelli FB, Dawson KA: Nanobiotechnology: nanoparticle coronas take shape. Nat Nanotechnol 2011, 6(1):11-2.

64. Albrecht C, Hohr D, Haberzettl P, Becker A, Borm PJ, Schins RP: Surfacedependent quartz uptake by macrophages: potential role in pulmonary inflammation and lung clearance. Inhalation toxicology 2007, 19(Suppl 1):39-48.

65. Haberzettl P, Duffin R, Kramer U, Hohr D, Schins RP, Borm PJ, Albrecht C: Actin plays a crucial role in the phagocytosis and biological response to respirable quartz particles in macrophages. Arch Toxicol 2007, 81(7):459-70.

66. Rothen-Rutishauser B, Muhlfeld C, Blank F, Musso C, Gehr P: Translocation of particles and inflammatory responses after exposure to fine particles and nanoparticles in an epithelial airway model. Part Fibre Toxicol 2007, $4: 9$

67. Geiser M: Update on macrophage clearance of inhaled micro- and nanoparticles. J Aerosol Med Pulm Drug Deliv 2010, 23(4):207-17.

68. Swanson JA: Shaping cups into phagosomes and macropinosomes. Nat Rev Mol Cell Biol 2008, 9(8):639-49.

69. Arredouani M, Yang Z, Ning Y, Qin G, Soininen R, Tryggvason K, Kobzik L: The scavenger receptor MARCO is required for lung defense against pneumococcal pneumonia and inhaled particles. J Exp Med 2004, 200(2):267-72.

70. Palecanda A, Paulauskis J, Al-Mutairi E, et al: Role of the scavenger receptor MARCO in alveolar macrophage binding of unopsonized environmental particles. J Exp Med 1999, 189(9):1497-506.

71. Arredouani MS, Palecanda A, Koziel H, et al: MARCO is the major binding receptor for unopsonized particles and bacteria on human alveolar macrophages. J Immunol 2005, 175(9):6058-64.

72. Nakamura M, Ishimura K: Rapid Size Evaluation of Nanoparticles Using Flow Cytometry. Advanced Science Letters 2010, 3:130-7.

doi:10.1186/1743-8977-8-31

Cite this article as: Scherbart et al: Contrasting macrophage activation by fine and ultrafine titanium dioxide particles is associated with different uptake mechanisms. Particle and Fibre Toxicology 2011 8:31.

\section{Submit your next manuscript to BioMed Central and take full advantage of:}

- Convenient online submission

- Thorough peer review

- No space constraints or color figure charges

- Immediate publication on acceptance

- Inclusion in PubMed, CAS, Scopus and Google Scholar

- Research which is freely available for redistribution 